\title{
Subject Positions and Information-Structural Diversification in the History of English*
}

\section{Theresa Biberauer}

University of Cambridge. Department of Theoretical and Applied Linguistics Stellenbosch University. Department of General Linguistics mtb23@cam.ac.uk

\section{Ans van Kemenade}

Radboud Universiteit Nijmegen. Faculty of Arts. Centre for Language Studies A.v.Kemenade@ let.ru.nl

\begin{abstract}
The aim of this paper is to integrate Information Structure/IS-related insights of past work on the subject system of Old English with a particular formal account of word-order variation and change in earlier English that did not take IS considerations into account. We offer a first detailed formal account of how the IS-sensitive Old English subject positions can be understood in the context of an OV system which was becoming increasingly VO, and thereafter outline subject-related developments during Middle English and Early Modern English, leading us to the present day. Against the background of these diachronic developments, our contention is that English has, in one way or another, exhibited IS-sensitive subject positions throughout its history and that, as argued by Kiss (1996), it continues to do so today.
\end{abstract}

Keywords: information structure; nature of spec; TP; OV/VO word order; subject positions; word order.

\section{Table of Contents}

\section{Introduction}

2. Information-sensitive subject positions in Old English (OE)

3. OE clausal syntax: word-order variation generated by a single grammar
4. Reconciling IS-sensitive subject positions with B\&R's word-order variation account

5. The further development of subject positions in the history of English

6. Conclusions and further questions

References

* The material in this paper was presented in whole or in part at the 13th Diachronic Generative Syntax conference, University of Pennsylvania at Philadelphia, and at the 20th International Conference on Historical Linguistics, National Museum of Ethnology, Osaka. We thank the audiences on these occasions, George Walkden and an anonymous referee for their comments. The usual disclaimers apply. 


\section{Introduction}

Subject positions have received considerable attention in research on English to date. In the diachronic domain, van Kemenade (1987) and Pintzuk (1991/1999) first pointed to the fact that personal pronoun subjects in Old English (OE) exhibit positioning effects that distinguish them from full nominal (DP) subjects, with van Kemenade $(1999,2000)$ and Haeberli (1999/2002) subsequently proposing a clausal structure in terms of which pronominal subjects occupy a higher position $\left(\mathrm{SU}_{1}\right.$ in (1) ) than that in which DP subjects appear $\left(\mathrm{SU}_{2}\right.$ in (1); cf. Cardinaletti 1997, 2004 for an in many ways parallel proposal for modern Italian;). The relevant structure, illustrating the key facts, is given in (1):

(1) $\left[_{\mathrm{CP}} \mathrm{XP} C\left[_{\mathrm{AgrP}} \mathrm{SU}_{1} \operatorname{Agr}\left[\left[_{\mathrm{TP}} \mathrm{SU}_{2} \mathrm{~T} \ldots\right]\right]\right]\right.$

More recently, the work of Bech (2001), van Kemenade \& Milicev (2005/2012), Westergaard (2005), van Kemenade, Milicev \& Baayen (2008), van Kemenade \& Los (2006), Hinterhölzl \& Petrova (2009), and van Kemenade \& Westergaard (2009, in press) has shown that the structure in (1) requires refinement as it fails to take account of information-structural (IS) considerations that clearly play a role in the placement of subjects. More specifically, these authors highlight the fact that $\mathrm{SU}_{1}$ in (1) may be occupied not only by personal pronouns, but also by specific, discourse-old DP subjects such as independently used demonstratives, and definite DPs, where definiteness is marked by a demonstrative pronoun. The relevant generalization, then, appears to be that this position is reserved for given/known/presupposed subjects, with the lower position being available for new subjects or those requiring focus. From this perspective, the OE 'subject field' can thus be seen to mirror the properties previously identified for both object and subject DPs in Germanic more generally (cf. i.a. Diesing 1992): old/defocused information surfaces to the left of new/focused information. As van Kemenade and colleagues show, this organization was ultimately lost during the Middle English (ME) period, although that loss may not have been total. Arguably, common consensus on present-day English (PDE) is that it is a language with a single canonical subject position - that designated Spec-IP during the GB era and most commonly referred to as Spec-TP in modern minimalist work. On this view, then, PDE does not feature an IS-sensitive subject position: all subjects, regardless of their discourse value, move to Spec-TP in order to satisfy a purely grammatical requirement, the so-called Extended Projection Principle (EPP) of Chomsky (1981 et seq.).

The purpose of this paper is to revisit the topic of early English subject positions, paying specific attention to IS considerations and the way in which these interacted with attested word-order variation. In particular, in the light of recent advances in the understanding of subject properties, of differences between $\mathrm{OV}$ and $\mathrm{VO}$ languages and the process of $\mathrm{OV}>\mathrm{VO}$ change, and of the formal representation of IS properties, we intend to focus on the following previously un(der)discussed synchronic and diachronic issues:

- the relation between the OE subject system and the language's supposed OV origins; and

— the factors which gave rise to the loss of this system in ME. 
We will also briefly consider subsequent developments, considering the extent to which the predominant generative view of the nature of the PDE subject system appears justified when diachronic facts are taken into account and pointing ahead to future work on this topic.

Our principal aim, then, is to offer a first detailed formal account of how the IS-sensitive OE subject positions can be understood in the context of an OV system which was becoming increasingly VO, and then to outline subject-related developments during ME and Early Modern English (EModE), leading us to the present day. Against the background of these diachronic developments, our contention is that English has, in one way or another, exhibited IS-sensitive subject positions throughout its history and that, as argued by Kiss (1996), it continues to do so today. Crucially, adopting this perspective allows an understanding of a number of phenomena that have previously received attention in the literature - notably, the persistent «low» occurrence of passive and unaccusative subjects (cf. i.a. van Kemenade 1997, Tanaka 2002, Warner 2007), the rise of Transitive Expletive Construction during the ME period (cf. Jonas 1996, Tanaka 2000, Links 2010) and the phenomenon of Post-finite Misagreement (cf. Grohmann \& Ingham 2009) - in a new and, we argue, genuinely illuminating light.

The structure of the paper is as follows: section 2 focuses on subject positions in OE, introducing the IS-sensitive positions identified by van Kemenade and colleagues in previous work. Section 3 introduces the formal analysis of $\mathrm{OE}$ word order proposed in Biberauer \& Roberts (2005 et seq.), with section 4 then interpreting the $\mathrm{OE}$ subject facts presented in section 2 in the context of this type of formal system. The aim of this latter section in particular will be to highlight the crucial interrelation between OV/VO variation and subject placement. As argued in more general terms by Biberauer \& Roberts (op.cit.), the loss of OV orders and the shift to general VO therefore had consequences for subject-related phenomena. Here we show that consideration of IS factors permits a more refined account of these consequences, an account which, crucially, leads us to expect the variability in subject behaviour attested in early Modern English (EModE). Section 5 focuses on the nature of this more refined account, the type of variability it predicts and how this can be understood as leading to a Kiss (1996)-type PDE subject system rather than a Chomsky (1981)-style system. Section 6 concludes.

\section{Information-sensitive subject positions in Old English (OE)}

As noted in the introduction, it was observed very early in the study of the history of English that the distribution of subjects in OE exhibited an asymmetry: while non-subject-initial main clauses ${ }^{1}$ featuring non-pronominal (henceforth: $D P$ ) subjects are generally Verb Second (V2), with the DP subject surfacing in immediate

1. Strikingly, $w h$-initial, negative-initial and pa/ponne-initial main clauses tended to exhibit V2, independently of the nature of the subject (cf. van Kemenade \& Los 2006 for overview discussion). The generalisation concerning non-subject-initial main clauses should thus not be taken to relate straightforwardly to main clauses featuring these first-position elements. 
postverbal position, corresponding clauses with pronominal subjects tended not to feature subject-verb inversion, with the pronominal subject preceding the finite verb; similarly, pronominal subjects systematically preceded diagnostic adverbial elements - specifically, the secondary negator not and high adverbs and particles including elements like $p a$ and ponne 'then',$n u$ 'now', eac 'also' and la 'lo'3, while DP subjects more commonly followed them. The relevant distributional differences are illustrated in (2-3) (diagnostic element [finite verb/secondary negator] underlined and subject in bold in each case) $:^{4}$

(2) a. Under Moyses $æ$ moste se bisceop habban an geæwnod wif, ... under Moses' law should the bishop have an espoused wife 'Under Moses' law, a bishop was to have an espoused wife, ...'

[ELS[Peter's_Chair]:218.2418]

b. Be ðæm we magon suiðe swutule oncnawan ðæt... by that we may very clearly perceive that 'By that we may very clearly perceive that ...'

[CP 26.181.16.1202]

(3) a. Ne het he us na leornian heofonas to wyrcenne... not ordered he us not learn-INF heavens to make 'He did not bid us to learn to make the heavens.'

[ELS [Memory of Saints]: 127.3394]

b. Ne sæde na ure Drihten pæt he mid cynehelme oððe not said not our Lord that he with diadem or mid purpuram gescryd, cumin wolde to us with purple clothed come wanted to us 'Our Lord did not say that He would come to us with a diadem or clothed with purple.'

[ELSS [Martin]: 762.6453]

As pronominal objects also commonly preceded the adverbial diagnostics, either along with a pronominal subject as in (3a) above or independently of a

2. Importantly, high discourse-oriented ponne (What, then, are your thoughts on this matter?) must be distinguished from the low temporal adverbial ponne (What did you do then?).

3. That the temporal elements mentioned here are high adverbials distinct from genuinely temporal elements can be both contextually and distributionally shown: besides surfacing in contexts where they clearly denote a literal time-related meaning, genuine temporal adverbials occupy a clausal position lower than that of their diagnostic counterparts. This is precisely what one would expect in terms of Cinque's (1999) hierarchy and Tenny's (2000) semantic interpretation of it: in terms of the latter, the CP-domain can be thought of as a speaker deixis zone in which «point-of-view» modality is expressed, while TP is the domain of temporal deixis. We can think of the IS-sensitive diagnostic elements originating from temporal adverbials as grammaticalised elements, which have undergone upward grammaticalisation (cf. Roberts \& Roussou 2003).

4. References to textual sources are based on the referencing system of the parsed corpora for Old and Middle English (Taylor et. al. 2003; Kroch \& Taylor 2000a), unless otherwise indicated. 
subject DP as in (4) below, it seems that the pre-diagnostic position in (1) may not in fact have been reserved for subjects, but that it might be best to think of it as a zone reserved for discourse-given elements, as indicated in (5) (adapted from van Kemenade \& Westergaard (in press); see further below):

(4) gif hine ðonne ðæt fleah mid ealle ofergæð, ðonne ne mæg he noht if him then the albugo with all covers then not can he naught geseon

see

'if it [the pupil of the eye] is entirely covered with albugo, he cannot see anything.'

[CP: 11.69.17.448]

(5) $\left[_{\mathrm{CP}} \mathrm{XP} C\left[_{\mathrm{AgrP}}\right.\right.$ Pronoun Subj $\left(\mathrm{SU}_{1}\right)$ - Pronoun Obj Agr $\left[_{\mathrm{AdvP} / \mathrm{NegP}} N e g / A d v\right.$ $\left.\left.\operatorname{Neg}\left[{ }_{\mathrm{TP}} D P \operatorname{Subj}\left(\mathrm{SU}_{2}\right) \mathrm{T} \ldots\right]\right]\right]$

As van Kemenade, in collaboration with various researchers, has shown, (5), however, does not facilitate any insight into why structures like (6) are also possible in $\mathrm{OE}$ :

(6) ... forðæm sio gesceadwisnes ðonne hæfð ofercumen ðæt mod \& because this wisdom then has overcome the.mind and gewielð subdued

'... because this wisdom (patience) has overcome and subdued the mind.'

[CP [Cotton]:33.218.19.42]

Structures in which DP-subjects precede rather than follow the adverbial diagnostics cited above are not uncommon, either in main or subordinate clauses, as Tables 1 and 2 (adapted from van Kemenade and Westergaard in press) clearly show:

Table 1. Relative position of adverb pa/ponne and pronominal vs DP subjects in main-clause questions

\begin{tabular}{lcc}
\hline \multicolumn{1}{c}{ OE main clauses } & Pronominal subjects & DP subjects \\
\hline Subject precedes pa/ponne & $90(98.9 \%)$ & $11(18 \%)$ \\
Subject follows pa/ponne & $1(1.1 \%)$ & $50(82 \%)$ \\
\hline Total & $91(100 \%)$ & $61(100 \%)$ \\
\hline
\end{tabular}

Table 2. Relative position of adverb pa/ponne and pronominal vs DP subjects in subordinate clauses

\begin{tabular}{lcc}
\hline \multicolumn{1}{c}{ OE subordinate clauses } & Pronominal subjects & DP subjects \\
\hline Subject precedes pa/ponne & $1116(99.6 \%)$ & $129(36 \%)$ \\
Subject follows pa/ponne & $5(0.4 \%)$ & $229(64 \%)$ \\
\hline Total & $1121(100 \%)$ & $358(100 \%)$ \\
\hline
\end{tabular}


In order to account for these patterns, van Kemenade and colleagues propose that the placement of OE subjects was in fact guided by information-structural (IS) considerations; specifically, the proposal is that discourse-referential (i.e. old/given/presupposed; henceforth: old) subjects occupy a higher clausal position, one to the left of the adverbial diagnostics discussed above, while discourse-new or focused (henceforth: new) subjects occupy a lower position to the right of these diagnostics. Van Kemenade, Milicev and Baayen (2008) provide explicit morpho-syntactic correlates for this generalization in quantitative terms: subjects occurring on the left of the diagnostic adverb typically belong to the nominal type personal pronoun, independently used demonstrative pronouns, or definite DP, and they have, with statistically very high significance, specific reference to an antecedent within four clauses in the preceding context. As also noted in van Kemenade, Milicev \& Baayen (2008) and van Kemenade (2009), OE featured a class of IS-sensitive demonstratives: the $s e$-series of weak demonstrative pronouns, which could also be used as independent pronouns and relative pronouns and which these authors argue signalled that a given nominal had specific anaphoric reference, i.e. that it had been previously mentioned. As such, we would expect the majority of $s e$-subjects to surface in $\mathrm{SU}_{1}$. We schematize the relevant structure as follows:

(7) $\left[_{\mathrm{CP}} \mathrm{XP} C\left[_{\mathrm{FP}}\right.\right.$ Discourse-Old Subj $\left(\mathrm{SU}_{1}\right) \mathrm{F}\left[_{\mathrm{Adv} / \mathrm{NegP}}\right.$ Neg/Adv Neg $\mathrm{C}_{\mathrm{TP}}$ Discourse-new Subj $\left(\mathrm{SU}_{2}\right) \mathrm{T} \ldots$ ]]]]

A few points are worth noting in relation to (7). Firstly, (7) differs from (5) in that $\mathrm{SU}_{1}$ is indicated as being located in FP rather than AgrP. Although we leave the precise designation of the position to which discourse-old subjects move to detailed future investigation, we regard it as likely that this position is located within an articulated $\mathrm{CP}$ - rather than the IP-domain (as $\mathrm{SU}_{1}$ in (5) would be). Following Frascarelli \& Hinterhölzl (2007) and Walkden (2010), who build on Rizzi (1997), one might, for example, view something like their familiar topic position (FamTopP), indicated in (8), as a plausible possibility:

(8) $\left[\right.$ ForceP $\left[\right.$ AboutTopP $\left[\right.$ ContrP $\left[\right.$ IntP $\left[\right.$ FocP $\left[\right.$ FamTopP* $\left[\right.$ FinP $\left[\right.$ IP $^{5}$

5. Following Hinterhölzl \& Petrova (2009), we can define the various Topic positions in (8) as follows:

a) ABOUTNESS TOPIC: «what the sentence is about» (Reinhart 1981, Lambrecht 1994); «what is a matter of standing and current interest or concern» (Strawson 1964);

b) CONTRASTIVE TOPIC: an element that induces alternatives which have no impact on the focus value and creates oppositional pairs with respect to other topics (Kuno1976, Büring 1999); and, finally,

c) FAMILIAR TOPIC: a given, discourse-linked constituent, which is typically destressed and realised in a pronominal form (Pesetsky 1987), generally used for «topic continuity» (Givón 1983). 
If FamTop is indeed recursive, as indicated above, the fact that it is not only old subjects which may occupy this position (cf. (3a) and (9) below), but additionally also pronominal objects (cf. (3a) and (4) above) can potentially be understood: ${ }^{6}$

(9) Pa se biscop pæt pa geseah, pe him big sæt... when the.DEM bishop that then saw who him by sat 'When the bishop, who sat next to him, saw that ...'

[Bede 3:4.166.8.1593]

Another point worth noting in relation to (7) is the fact that a purely semantic account, in terms of which $\mathrm{SU}_{1}$ is occupied by presupposed as opposed to «novel» subjects, cannot fully account for the OE subject-placement facts; the discourserelated activation/accessibility/ prominence/salience of old subjects is evidently crucial in determining their compatibility with pre-/post-diagnostic placement (cf. i.a. Chafe 1976, 1987, Prince 1981, 1992, Reinhart 1981, Ariel 1988, Vallduví 1992, Gundel, Hedberg \& Zacharski 1993, Lambrecht 1994, Dryer 1996, McNally 1998, López 2009 on these notions). Thus van Kemenade \& Milicev (2005:2223) observe that not just indefinite DPs, but also definite DPs may occur in $\mathrm{SU}_{2}$ position:

(10) Gif donne se sacred bið ungerad ðæs lareowdomes, hwæt if then the.DEM priest is unskilled the ecclesiastical-authority what forstent ðonne his gehyld?

avails then his cry

'If the priest is unskilled in ecclesiastical matters, what does his cry matter?

[CP 15.91.25]'

In (10), se sacred («the priest») is interpreted as «whoever has the property of being a priest», i.e. attributively/generically. Notably, accessibility/discourse prominence can also be seen to play a crucial role in determining whether object pronouns undergo fronting (as in (3a) and (9)) or not (cf. van Kemenade \& Milicev 2005/2012: 6-7). Van Kemenade \& Milicev (2005/2012) also note that otherwise low DPs, e.g. indefinite pronouns, may occasionally surface pre-diagnostically rather than in their more usual post-diagnostic position. This is true for unmodified man («one», which in contrast to modified forms like anige mon («anyone») and hwylc man («whichever one»), always precedes ponne (cf. van Bergen 2002). They treat these instances of mon as impersonal pronouns with an implicit discourse referent. Specific indefinites may also occur on the left of the diagnostic.

6. See van Kemenade \& Milicev (2005/2012) for more detailed discussion, which also raises the possibility that one of the pre-diagnostic positions may be a contrastive topic position, which is compatible with (8). Note, however, that a non-cartographic approach of the kind proposed by Neeleman, van de Koot, Titov \& Vermeulen (2010) may also facilitate insight into the precise structure of the pre-diagnostic field. 
Thirdly, in addition to the above, we also find structures like (11) in which both $\mathrm{SU}_{1}$ and $\mathrm{SU}_{2}$ are filled and the higher and lower subjects are coreferential:

(11) Ond mid by he $\underline{\text { da }}$ se geonga apeling ana pær pa gyt sæt ... and with that he then the.DEM young prince alone there then still sat 'And as the young prince still sat there alone...'

[Bede 2:9.130.20.1246]

These structures may surface in a context where an individual/entity has been previously mentioned, but needs to be reactivated. As such, we can understand the pronoun as signalling the referent's old-information status, while the full DP marks the fact that the referent is no longer salient.

Thus far we have considered potential subject positions external to the thematic domain, vP. The empirical evidence, however, clearly points to at least one additional vP-internal subject position. Consider the following data:

(12) a. for pan ðe nu todæig us eallum is purh hire for that that now today to-us all is through her geearnungum hæl geyht deserts happiness increased

'For now today, through her deserts, happiness is increased to us all.'

[AECHom_I,_30:434.163.5977]

b. Noe eac for his rihtwisnysse ofercom pæt miccle flod pe ealne Noah also for his righteousness overcame the great flood which all middaneard ofereode swa pæt ðurh hine wearð eft eall mancynn the-earth overflowedso that through him was again all mankind geedstapelod

restored

[coaelive, $\left.+A L S \_\left[M e m o r y \_o f \_S a i n t s\right]: 22.3347\right]$

c. Pa wæs him eallum gesegen, swa swa hit wæs, pæt him wære from then was them all seemed so as it was that him were by Drihtne sylfum heofonlic gifu forgifen the-Lord himself heavenly grace granted 'Then it seemed to them all, as indeed it was, that a heavenly grace had been vouchsafed him by the Lord himself.'

[Bede_4:25.344.23.3465]

Here we see that the subjects of unaccusative and passive verbs, i.e. internalargument (IA) subjects, appear to be able to surface in a position significantly lower than the two we have been considering until now. Van Kemenade (1997) offers detailed discussion of the range of predicates that permitted unraised subjects, showing that these also include impersonals, posture verbs, (manner of) motion verbs, come, go, and so on. For present purposes, the significance of data like that in (12) is its indication of the fact that we must differentiate at least three 
subject positions in $\mathrm{OE}$, two within the T/CP domain and at least one within the vP-domain.

This concludes our overview of the range of OE subject positions. In the following section, we turn to the formal analysis of OE clause structure within which we believe these subject-related facts can be insightfully embedded and understood.

\section{OE clausal syntax: word-order variation generated by a single grammar}

\subsection{Introduction}

As is well known, OE exhibited both OV and VO word orders (cf. Fischer, van Kemenade, Koopman \& van der Wurff 2000 for overview discussion and further references). One approach to this state of affairs is to view it as a «double base» system, in which OV and VO grammars engaged in «competition» (cf. Kroch 1989), which was ultimately won by the VO grammar (cf. i.a. Pintzuk 1991/1999, Kroch \& Taylor 2000b, and much subsequent work by Susan Pintzuk \& Ann Taylor in particular). An alternative view is that a single grammar gives rise to the observed word-order variation. This is the perspective adopted by Biberauer \& Roberts (2005 et seq.), on whose work we will be basing our in-depth analysis of OE subject positions.

According to Biberauer \& Roberts (henceforth: B\&R), canonical OVAux orders in OE crucially involve vP-fronting to Spec-TP. At first sight, this assumption would seem to render B\&R's analysis incompatible with the (partial) cartography of subject positions in (7), in terms of which Spec-TP is in fact the position reserved for new subjects. What we will show in Section 4, however, is that this superficial impression is incorrect, and that B\&R's analysis of $\mathrm{OE}$ and $\mathrm{ME}$ in fact facilitates a formal understanding of the properties of the IS-sensitive OE subject system and the way in which this changed in ME. First, however, we have to establish how B\&R's system derives OV and VO orders in OE.

\subsection{The mechanics of $B \& R$ 's approach to $O E$ word-order variation}

B\&R follow Kayne (1994) in assuming that head-final structures are necessarily derived via movement (see Biberauer, Holmberg \& Roberts 2009, 2010 for extensive further justification of this idea). For OE OVAux orders specifically and earlier and modern West Germanic OVAux orders more generally, they assume the following sequence of derivational steps: 
(13) (i) Merge of $\mathrm{V}$ and internal argument (here: $O$ ), giving a head-initial $\mathrm{VP}^{7}$

(ii) Merger of $\mathrm{v}$ and $\mathrm{V}$-to- $\mathrm{v}$ raising

(iii) VP remnant movement to inner Spec- $\mathrm{vP}^{8}$

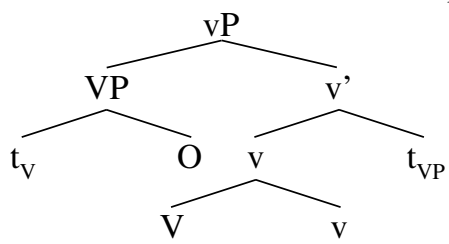

(iv) Merger of the external argument (here: $S$ ) in a further (higher) SpecvP:

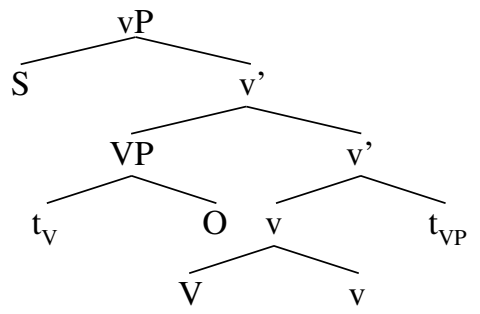

(v) Merger of T (here: Aux) and vP-movement to SpecTP:

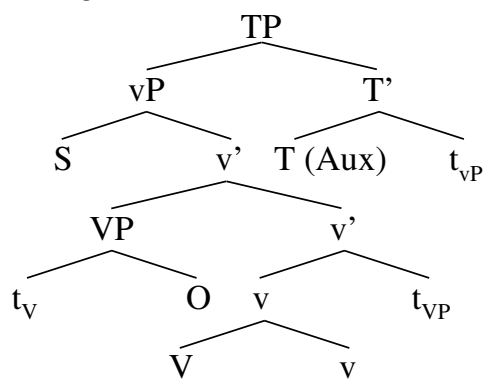

7. It is in fact possible that this merger is followed by movement of $\mathrm{O}$ to Spec-VP under the influence of a c-selection-related movement trigger (represented by ${ }^{\wedge}$ in Biberauer, Holmberg \& Roberts 2009, 2010). If this is correct, OE VP will not in fact be head-initial, as indicated in (13i). Crucially, Biberauer et al. (op. cit.), following Julien (2002a), argue that c-selection-related movement necessarily entails «roll-up» movement, i.e. comp-to-spec movement, delivering rigidly head-final orders. «Roll-up» movement can be shown to differ from more familiar «rolling stone» movements (cf. Travis 2006), which typically involve Spec-to-Spec movement (the exception involving internal arguments initially merged as complements). One important difference is that specifiers generated by Spec-to-Spec movement exhibit so-called freezing effects (cf. Corver 2006), while specifiers generated by «roll-up» movement (i.e. rigidly head-final structures) do not - consider, for example, the ubiquity of scrambling phenomena in rigidly head-final languages. As this matter is not of central importance in the context of the present paper, we leave it aside here.

8. In assuming multiple specifiers, B\&R clearly depart from Kayne's rigid phrasal template (SpecHead-Comp). If these multiple-specifier structures are sent to Spellout with more than one of the specifiers containing material which is to be overtly realised - a scenario which arises in $\mathrm{OE}$ and also in West Germanic more generally on B\&R-style analyses - it will clearly fall foul of the LCA, as defined by Kayne (1994). As linearization is not of central relevance to us in this paper, we leave this non-trivial matter to future research (see Biberauer 2011 for discussion). 
As shown in $(13 \mathrm{v})$, fronting of the SOV-containing vP to Spec-TP results in SOVAux ordering wherever T is occupied by an auxiliary. As Biberauer \& Roberts $(2006,2009,2010)$ note, however, it is unlikely that OE auxiliaries would have been T-elements, with the result that we either need to assume an additional verbal head, merged above vP and below TP in a monoclausal structure (feasible for more grammaticalised/«functional» auxiliaries), or a biclausal structure in which auxiliaries retaining certain lexical properties (cf. Lightfoot 1979, Roberts 1985, Warner 1993) are merged as V which, in turn, selects a (potentially reduced) clausal complement of some kind. This refinement does not affect our central argument here, which is that Spec-TP in OE OVAux structures was the position to which a verbal XP in T's c-command domain raised. For convenience, we will continue to refer to the raising $\mathrm{XP}$ as $\mathrm{vP}$.

In addition to rigidly head-final OVAux structures, OE also permitted OV structures featuring a greater or lesser amount of postverbal material (so-called leaking structures). To account for these, B\&R appeal to the idea that identical Agree relations in a given grammar may give rise to superficially different word orders as a consequence of the fact that Agree-related movement may under certain circumstances involve movement of just the Goal («stranding») on the one hand or of the Goal and its immediately containing structure («piedpiping») on the other. The definition of Agree assumed by B\&R is given in (14):

(14) Agree is a relation between two heads $\mathrm{X}$ and $\mathrm{Z}$, where the following conditions hold:

a. X, the Probe, asymmetrically c-commands Z, the Goal;

b. $X$ and $Z$ are non-distinct in formal features;

c. $\mathrm{X}$ and $\mathrm{Z}$ are active, i.e. bear unvalued features making them visible to the computational system;

d. there is no third head $\mathrm{Y}$ which intervenes between $\mathrm{X}$ and $\mathrm{Z}$ which would be able to Agree with $X$ (i.e. there is no head $Y$ bearing features of the relevant type which asymmetrically c-commands $\mathrm{Z}$ but not $\mathrm{X}$ ).

Consider the abstract Probe-Goal configuration in (15):

(15) a.

... XPROBE ... [YP ... Z ZGOAL ... ] ...

b.

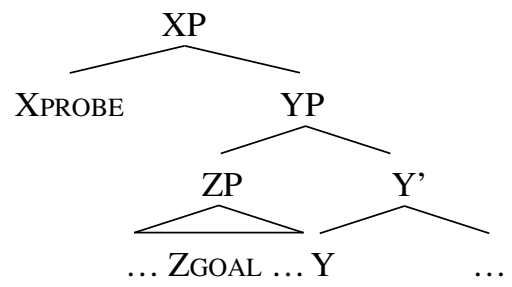

Here, a head $\mathrm{X}$ bearing one or more unvalued features (for expository convenience, we will present our discussion in terms of single unvalued features) acts as a Probe in search of a valued counterpart of its unvalued feature. This it finds on the 
Goal, Z, which is located in its c-command domain and which, in turn, bears an unvalued feature of its own, rendering it active and therefore visible to the Probe. Agree between the Probe and Goal results in the valuation of the unvalued features on both heads. Feature valuation, which corresponds to the feature checking of earlier versions of the theory (cf. Chomsky 1995), is therefore achieved without movement. For movement to take place, a Probe must bear an additional movement-triggering feature, conventionally referred to as an EPP-feature (although see Chomsky 2007 et seq. on so-called Edge Features and Biberauer, Holmberg \& Roberts 2009, 2010 on ^, a generic movement diacritic, which may be associated with different properties of a head). Following Richards \& Biberauer (2005) and Biberauer \& Richards (2006), B\&R assume that Universal Grammar (UG) offers various parametric options in respect of the 'size' of the constituent that undergoes movement wherever $\mathrm{X}$ probes $\mathrm{Z}$ and also bears an EPP-feature (i.e. movement diacritic).

In the case where the Probe $X=T$, the Goal $Z=a$-feature (or, more probably, the $\phi$-features associated with an active DP) and $\mathrm{Y}=\mathrm{v}$, we therefore expect the following range of movement possibilities:
(16) a. D-movement only:$$
\left[{ }_{\mathrm{TP}} \mathrm{D}-\mathrm{T}\left[{ }_{\mathrm{vP}} \ldots[\mathrm{DP} \ldots \text { (D) } \ldots]\right]\right]
$$
b. DP-movement only:$$
\left[{ }_{\mathrm{TP}} \mathrm{DP} \quad \mathrm{T}\left[{ }_{\mathrm{vP}} \ldots(\mathrm{DP}) \ldots\right]\right]
$$
c. Obligatory piedpiping:

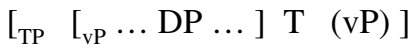
d. Optional piedpiping:

$$
\begin{aligned}
& {\left[{ }_{\mathrm{TP}} \mathrm{DP} \quad \mathrm{T} \quad\left[{ }_{\mathrm{vP}} \ldots(\mathrm{DP}) \ldots\right]\right] \text { AND }} \\
& {\left[_{\mathrm{TP}}\left[{ }_{\mathrm{vP}} \ldots \mathrm{DP} \ldots\right] \mathrm{T}(\mathrm{vP})\right]}
\end{aligned}
$$

(16a) involves adjunction of the D-head of the DP-subject to the probing T-head, a movement operation that has been argued to take place in various VSO languages (cf. Travis 2006 for recent discussion). (16b) instantiates the mode of EPP-satisfaction standardly assumed for D-seeking T in PDE (and many other languages), i.e. subject DP-raising to Spec-TP. (16c), in turn, represents a mode of EPP-satisfaction that Richards \& Biberauer (2005) and Biberauer \& Richards (2006) argue to differ minimally from those more standardly assumed: instead of a D-head (which could in principle also be associated with finite V; cf. Alexiadou \& Anagnostopoulou 1998) or DP undergoing raising to Spec-TP, it is also possible that either of these D-bearing categories may constitute the Goal of Agree, while a larger category properly containing this Goal is targeted for movement. In other words, the idea is that the distinction between the two related properties that a Probe may have in the context of Chomsky's Probe/Goal/Agree system, namely that of being a Probe on the one hand and that of being associated with one or more EPP-features on the other, can be exploited in order to understand parametric variation: in terms of this system, it does not follow that the category that a given head probes has to correspond to the category that ultimately undergoes movement under the influence of the Probe's EPP-feature; as long as the moving category contains the Goal, the computational system will «not mind». Against that background, it can be seen that 
$(16 \mathrm{c}, \mathrm{d})$ differ from $(16 \mathrm{a}, \mathrm{b})$ only in respect of the «size» of the moved category: the Goal in this case may once again be either an active D or DP in the vP-domain, but the category that undergoes movement is $\mathrm{vP}$, i.e. the category that immediately contains the D(P)-Goal. Richards \& Biberauer (2005) and Biberauer \& Richards (2006) propose that inflectionally rich German represents a language in which T Agrees with D-on-V and then moves the entire vP to Spec-TP (so-called head-piedpiping). Inflectionally more impoverished Dutch and Afrikaans, by contrast, are argued to be languages which target the subject DP, but then move the whole containing $\mathrm{vP}$ (so-called spec-piedpiping). Although $\mathrm{OE}$ was inflectionally quite rich and it is also conceivable that Proto-Germanic could have been a head-piedpiping system, various considerations point to $\mathrm{OE}$ itself having been spec-piedpiping.

The key property of piedpiping modes of EPP-satisfaction in the present context is that they, under currently rather poorly understood circumstances, appear to permit formal optionality which is not available to languages employing nonpiedpiping modes of EPP-satisfaction (i.e. D- or DP-raising as in (16a,b) above). In particular, there appear to be synchronically attested languages that allow EPP-satisfaction via vP-raising (i.e. piedpiping) to alternate with satisfaction via DP-raising (i.e. stranding), modern spoken Afrikaans and various dialects of German and Dutch being cases in point (cf. Biberauer \& Richards 2006, Biberauer \& Roberts 2006). Similarly, B\&R propose that earlier stages of English permitted piedpiping modes of EPP-satisfaction that were ultimately replaced by the (16b) mode that holds of PDE. With this background in place, we can now consider the significance of these proposals for OE word-order variation, on the one hand, and $\mathrm{OE}$ subject placement on the other.

\section{3. $B \& R$ 's formal system applied to $O E$ word order}

$\mathrm{B} \& \mathrm{R}$ assume that both $\mathrm{v}$ and $\mathrm{T}$ in $\mathrm{OE}$ were associated with EPP-features that could be satisfied either by movement of the Goal alone (i.e. DP-movement) or by movement of the category immediately dominating the Goal-DP (i.e. VP- or vP-movement). In respect of the satisfaction of the EPP-features on $v$ and T, therefore, OE was an optional piedpiping language of the kind schematized in (16d) above. More specifically, it permitted the following EPP-satisfaction options in the $\mathrm{vP}$ - and TP-domain respectively (piedpiping vs stranding options aside, the derivations were assumed to proceed as indicated in (13)):

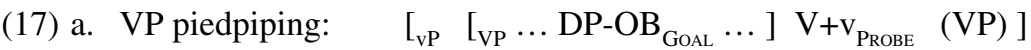

b. VP 'stranding': $\quad\left[_{\mathrm{vP}} \quad \mathrm{DP}^{-\mathrm{OB}_{\mathrm{GOAL}}} \mathrm{V}+\mathrm{v}_{\mathrm{PROBE}}\left[\left[_{\mathrm{VP}}\right.\right.\right.$.. (DP) ... $\left.]\right]$

(18) a. vP piedpiping: $\left.\quad \int_{\mathrm{TP}}\left[_{\mathrm{vP}} \mathrm{DP}_{-} \mathrm{SU}_{\mathrm{GoAL}} \mathrm{VP} \mathrm{V}+\mathrm{v}\right] \mathrm{T}_{\mathrm{PROBE}}(\mathrm{vP})\right]$

b. vP 'stranding': $\quad\left[{ }_{\mathrm{TP}} \mathrm{DP}-\mathrm{SU}_{\mathrm{GoAL}} \mathrm{T}_{\mathrm{PROBE}}\left[{ }_{\mathrm{vP}}(\mathrm{DP}) \ldots\right]\right]$

Let us firstly consider the v-related movement operations schematically represented in (17) above and illustrated in (19) below (Goal underlined and moved 
category boldfaced in each case; lower, ultimately unpronounced copies indicated in brackets):

(19) Satisfaction of v's D(object)-oriented EPP-feature:

a. VP piedpiping:

... pæt ic [ ${ }_{\mathrm{VP}}$ bas boc to Engliscre spræce (V)] awende+v (VP) that I this book to English tongue translate

'... that I translate this book into English].'

[AHTh, I, pref, 6; van Kemenade 1987: 16]

b. VP piedpiping:

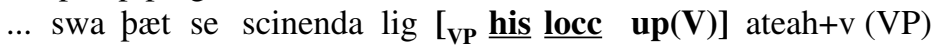

so that the shining flame his locks up- drew

'... so that the shining flame drew his locks up.'

[ECHom II, 39.1.295.241; Fischer et al. 2000: 189]

c. VP stranding (i.e. sole movement of the Goal):

Dunn hafað [ ${ }_{\mathrm{DP}}$ bas boc $]$ gesald $+\mathrm{V}[\mathrm{VP}$ his wife (V) (DP)]

Dunn has this title-deed given his wife

'Dunn has given this title-deed to his wife.'

[ch1514(Rob9)1); Koopman 1994: 59]

d. VP-stranding:

ðe he $\left[_{D P}\right.$ hine] ætbræd+v [VP fram flæsclicum lustum (V) (DP)]

that he himself withdrew from fleshly lusts

'.. because he had withdrawn himself from fleshly lusts.'

[AHTh, I, 58; van Kemenade 1987: 34]

In (19a), the Goal probed by $\mathrm{v}$ is the direct object pas boc. In moving to SpecvP under the influence of v's EPP-feature, this Goal piedpipes the additional material contained in VP (i.e. to Engliscre sprace (V)), with the result that the lexical verb ultimately surfaces string-finally. In (19c), by contrast, the same Goal (bas boc) moves independently of the remaining material in VP, giving the surface effect of «leaking»/extraposition. ${ }^{9}$ Both structures converge because an XP containing the Goal moves to the specifier of the probing v. (19b) is like (19a) in being the output of a derivation involving VP piedpiping: in the context of the analysis proposed in $\mathrm{B} \& \mathrm{R}$, in terms of which $\mathrm{V}$ consistently raises to $\mathrm{v}$, it is clear that orders

9. In actual fact, «leaking» is the consequence of the fact that B\&R assume Chomsky's (2001) Phase Impenetrability Condition (PIC) to entail that material in the complement of a phase head (v, C, etc.) is radically removed from the computation at the relevant points rather than just being rendered opaque for subsequent Agree operations. Upon being removed from the computation - B\&R's radical spellout - material sent to the interfaces is immediately interpreted; at PF, this includes immediate linearization, with each successive spellee (cf. Kahnemuyipour 2009) being independently linearized and then spelled out to the left of already-realised material. If v's EPP-feature is satisfied by object-raising (stranding), the material remaining in VP will therefore be sent to PF upon completion of the vP phase. This, then, results in the final placement of «leaked» elements. 
like (19b) must involve movement not only of the probed object-DP, but also of the verbal particle; $B \& R$ propose that these elements raise together as another case of VP piedpiping (cf. Elenbaas 2007 for further discussion). Particle-verb structures, alongside rigidly verb-final structures such as that illustrated in (19a), therefore constitute a key piece of data indicating the availability of VP piedpiping as a means of satisfying v's EPP-feature. (19d), in turn, represents further evidence (alongside (19c)-type structures) that VP-stranding is also an option: here the reflexively used personal pronoun constitutes the Goal probed by v, with only this element undergoing raising under the influence of v's EPP-feature and the PP being stranded when the object undergoes movement.

The T-related modes of EPP-satisfaction available in OE are illustrated in (20) (Goal and moved category indicated as before):

(20) Satisfaction of T's D(subject)-oriented EPP-feature:

a. vP piedpiping:

... pæt $\left[_{\mathrm{vP}}\right.$ bæt folc Gregorium to papan gecoren ] hæfde (vP) that the people Gregory to pope elected had

'... that the people had elected Gregory as pope.'

[ÆCHom_II,_9:75.102.1510]

b. vP stranding:

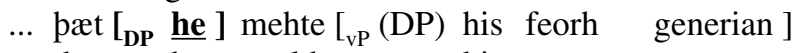
that he could his property save

'... so that he could save his property.'

[Or_2:5.48.13.927]

(20a) illustrates the structure that results when the subject-Goal of the T-Probe piedpipes the vP within which it is contained. Note that this typically West Germanic SOVAux ordering also requires piedpiping satisfaction of v's EPP-feature, i.e. although Gregorium is the Goal of v, it must piedpipe the rest of VP to deliver $\left[_{\mathrm{vP}}\right.$ ${ }_{\mathrm{VP}}$ Gregorium to papan] gecoran+v] prior to the merger of the subject-DP. In (20b), only the subject-Goal, he, undergoes movement to Spec-TP, with the consequence that the remaining vP-internal material his feorh generian or his feorh, depending on one's analysis of the structure(cf. Biberauer \& Roberts (2006) for further discussion) surfaces in post-T position. In this case, the $\mathrm{OV} v \mathrm{P}$ could have been generated either via object DP-raising or via VP-piedpiping since there is no additional, non-object material to decide the matter for us: where this surfaces preverbally, however, v's EPP-feature would have been satisfied by piedpiping; where it surfaces postverbally, the «stranding» option (sole Goal movement) would have been taken.

We can now consider the range of word-order variation that we would expect to find in OE (leaving aside V2 and V3 orders, resulting from further verb and XP-movement into the domain dominating $\mathrm{T}$ ). The following options would have been available in monoclausal structures ( $X$ in each case signals «leaked» VP-internal material, which is linearised in final position owing to the operation of the «radical spellout» operation outlined in note 9): 
(21) a. VP- and vP-piediping: SOVAux

b. VP-stranding and vP-piedpiping: SOVAuxX

c. VP-piedpiping and vP-stranding: SAuxOV

d. VP- and vP-stranding: SAuxOVX

In bi-clausal auxiliary-containing structures ${ }^{10}$, we expect a further range of options. The details will take us too far afield here (cf. Biberauer \& Roberts 2006, 2008, 2009 for discussion), but the key point for our purposes is the fact that the piedpiping and stranding options in restructuring structures give rise to still further orders. Specifically, these structures may be SOVAux (consistent piedpiping) and (non-V2) SAuxOV (VP-piedpiping in the lower clause, followed by consistent stranding), as in the monoclausal case, and, additionally, SOAuxV and SAuxVO, the precise derivation of which depends on whether the restructuring verb (Aux) is a raising or a control predicate. ${ }^{11}$ Where the final element is followed by some $\mathrm{X}$ (i.e. SOVAuxX, SAuxOVX and SOAuxVX respectively), the lowest movement (aimed at satisfying subordinate-clause v's EPP-requirement) would have been stranding rather than piedpiping. ${ }^{12}$

Given the above, we can see that B\&R's single-grammar piedpiping approach to $\mathrm{OE}$ word order is able to generate the range of attested word orders (while ruling out the unattested *VOAux order (though see note 13); cf. B\&R and also Biberauer, Holmberg \& Roberts 2010 for discussion). Before we return to our principal concern in this paper, namely offering a formal account of the IS-sensitive subject positions in $\mathrm{OE}$, one more property of the grammar of $\mathrm{OE}$ needs to be addressed: the possibility of a range of VO-structures.

Worth noting in connection with the VO-orders already mentioned above is that they, like the SVO and SVAuxO («Stylistic Fronting»; see below) orders that we have not mentioned so far, may be derived in more than one way. So, for example, we have already indicated that SAuxVO may be generated either via VP-piedpiping

10. As noted above, we do not commit ourselves specifically to a view on which auxiliary-containing structures in OE were monoclausal and which were biclausal. Following B\&R (2006, 2008, 2009), however, we assume that V-Aux orders - associated with restructuring (i.e. Verb (Projection) Raising, cf. Haegeman \& van Riemsdijk 1986 and Wurmbrand 2001) - entail a biclausal structure.

11. Note that $\mathrm{V}$ surfaces in post-auxiliary position in both of these latter cases owing to the fact that it raises to infinitival T in restructuring structures (cf. Biberauer \& Roberts 2006, who build on Kayne 1991 and Roberts 1997, for elaboration of this idea). Wherever it fails to undergo raising into the matrix clause (stranding cases), post-auxiliary placement results. For raising predicates, we assume the embedded subject to undergo either piedpiping or independent DP-raising into the main clause; for control predicates, we assume the infinitival subject to be PRO, while the matrix clause features a distinct overtly-merged subject, which may undergo the usual piedpiping or standing options when it is probed by matrix $\mathrm{T}$.

12. For SAuxVOX, however, either piedpiping or stranding could have taken place: wherever V moves to infinitival T (see previous note) and VP-internal material is stranded within the infinitival vP, it will be impossible to tell what kind of movement has taken place lower down in the clause. As we will indicate in section 5.1, this surface ambiguity plays an important role in B\&R's account of the $\mathrm{OV}>\mathrm{VO}$ change in the history of English. 
or DP-raising to satisfy v's EPP-requirement in the infinitival clause. Additionally, like objects in other West Germanic languages, $\mathrm{O}$ may or may not have undergone scrambling to the edge of the $\mathrm{vP}$ (cf. section 4.2). The significance of this option will become clearer below, but the key point for present purposes is that clausefinal objects, just like objects in other positions, are expected, on B\&R's analysis, to be both new and old in IS terms: where an object has simply undergone probedriven movement to Spec-vP, it will be interpreted as new/focused, whereas an object which has undergone further scrambling will receive the standard West Germanic «defocused»/old reading. This is crucial in view of recent work by Taylor $\&$ Pintzuk (this volume).

That SVO orders may also be derived in multiple ways, with IS considerations being central, can also easily be shown. Thus, in main clauses, $\mathrm{O}$ may once again have undergone one or both of the vP-internal movements outlined above, while the positioning of $\mathrm{S}$ will also be determined on the basis of whether $\mathrm{S}$ is new or old (we discuss the precise movement operations involved in the following section); furthermore, $\mathrm{V}$ may raise to different heads - specifically, if we adopt the structure in (7), T or F-depending on the nature of S and whether the structure is V2 or not .

«Stylistic Fronting» SVAuxO structures are particularly significant in the context of B\&R's proposal since the prediction of the proposal outlined above for these structures would be that they will not in fact be able to feature direct objects. Let us consider why.

For B\&R, OE objects necessarily undergo raising to Spec-vP (either as part of a remnant VP in accordance with the piedpiping option, or independently, via DP-raising in accordance with the stranding option). In main clauses, this means that $\mathrm{vP}$-raising, which would be necessary to derive the pre-Aux position of $\mathrm{S}$ and $\mathrm{V}$, would give rise to SOVAux ordering, i.e. a non-Stylistic Fronting structure. In biclausal structures, in turn, infinitival $\mathrm{V}$ will raise to $\mathrm{T}$, as outlined in note 11 , which means that vP-raising into the main clause would again be required to deliver SVAux order. In this case too, however, there is no way to raise $\mathrm{S}$ and $\mathrm{V}$ independently of $\mathrm{O}$ if $\mathrm{O}$ is located in Spec-vP. ${ }^{13}$ The prediction that OE SVAuxstructures are restricted to object-less structures does not, however, appear to be correct. Consider the following example from Taylor \& Pintzuk (this volume).

13. This state of affairs, of course, has important consequences for the Final-over-Final Constraint in terms of which SVOAux orders are categorically absent from all attested stages of English and, indeed, Germanic languages and languages more generally (cf. Biberauer, Holmberg \& Roberts 2010 for discussion): while it is not possible to raise $\mathrm{S}$ and $\mathrm{V}$ independently of $\mathrm{O}$ on the proposed system, it is possible to raise $\mathrm{S}, \mathrm{V}$ and $\mathrm{O}$, giving rise to SVOAux ordering. Worth noting here, though, is that the subject in the structures under consideration necessarily raises to Spec-TP of the infinitival clause via spec-to-spec («rolling stone») rather than piedpiping («snowballing») movement. Just as Biberauer, Holmberg \& Roberts (2010) argue that heads triggering linearizationdriven comp-to-spec movement (which therefore also results in the surface effect of «snowballing», or rigid head-finality) cannot select heads triggering either spec-to-spec or no movement (i.e. head-initial heads), it seems to be the case that probe-driven spec-to-spec movement (resulting in head-initiality) cannot be derivationally followed by probe-driven piedpiping (resulting in head-finality). The precise details of this matter must remain for future research. 
(22) ... pæt he friðian wolde pa leasan wudewan that he make-peace would the false widow '... that he would make peace with the false widow.'

[ELS_[Eugenia]: 209.315]

In view of the availability of structures of this type, we propose a refinement of B\&R's (2005) general analysis of OV word order in OE which also anticipates the analysis of ME word order (see section 4.5 below for more detailed discussion). As noted above, B\&R assume v's probing of object-DPs to give rise either to VP-piedpiping or object-DP raising (stranding). Since it is clearly the case that IS considerations played a role in OE object-placement, however, a more precise characterisation of the piedpiping options available in the VP-domain would reflect these considerations. Building on Biberauer \& Roberts's $(2008,2009)$ analysis of early ME, we therefore propose that the OE VP-piedpiping/DP-raising optionality did not in fact affect all objects, but only two sub-classes, namely those bearing a negative feature and those expressing old information (see section 4.5 for the mechanics of this proposal). For the moment, the key point is that it entails that OE objects differed from subjects in not uniformly undergoing raising under the influence of a probing head, but that IS-considerations are, once again, central. More specifically, the proposal entails that SVO, SAuxVO and SVAuxO («Stylistic Fronting») orders could be generated in various ways by the grammar, not all of which entailed object-raising. Of these orders, we have not so far discussed SVAuxO, owing to the fact that it is not one that would be generated by the earlier, unattested, but, by hypothesis consistently object- (and, possibly initially, consistently VP-) raising OE grammar. In later, attested OE, after the loss of systematic object-raising, however, this order would also have resulted where T's EPP-requirement was satisfied via $\mathrm{vP}$-piedpiping: wherever objects failed to raise in the vP-domain, vP would contain only the raised V (cf. (13iii) above), optional material merged within this domain and the subject, thus giving rise to surface $\mathrm{S}(\ldots)$ VAuxO.$^{14}$ We return to these orders in section 4.5 below.

Summarising as regards VO-orders, then, we see that these are particularly amenable to multiple derivations, rendering them ambiguous input from the perspective of the language acquirer. This is a non-trivial circumstance, given the subsequent history of English word order and, as we will see, subject positions.

With this formal background in place, we are now in a position to consider how B\&R's system might give us an insight into the available OE subject positions and also how these changed over time.

14. As Aux would have undergone further movement in main clauses (cf. the discussion of left-peripheral verb movement in section 2.1 above), it is clear that this «Stylistic Fronting» derivation would not always have been detectable from surface facts; in subordinate clauses, however, its occurrence would be clear (cf. Biberauer \& Roberts 2006 for further discussion and references). 


\section{Reconciling IS-sensitive subject positions with B\&R's word-order variation account}

\subsection{Introduction}

We return now to the problem stated at the start of the previous section, namely that Spec-TP on B\&R's approach clearly cannot be viewed as a designated subject position, as suggested in (7): where piedpiping options are (non-trivially ${ }^{15}$ ) taken, some form of vP would occupy Spec-TP. External-argument subjects (henceforth: $E A s$ ) would always raise along with vP, but internal-argument subjects and objects more generally (henceforth: IAs) would only do so if they had undergone raising into the $\mathrm{vP}$, i.e. in the presence of a movement trigger on $\mathrm{v}$, which we are assuming to have been present only in the case of negative and old IAs; in accordance with radical spellout (cf. note 9), unraised IAs would be sent to spellout prior to vP-raising, resulting in their being linearised in final position, as shown below:

(23) a. Se mæssepreost sceal mannum bodian pone sopan geleafan the masspriest must people preach the true faith 'The masspriest must preach the true faith to the people.'

[AECHom II, 22.194.148]

b. purh ða wifunge sind getacnode pæs lichaman lustas through the wife-taking are signified of-the body lusts 'The body's lusts are signified by taking to wife.'

[AECHom I, 26.215.72]

In the following section, we will concentrate on what has often been described as OE's 'OV grammar' (cf. the references to double-base approaches given in section 3.1 above), i.e. in our terms, that in which objects obligatorily underwent raising to Spec-vP, either via piedpiping or stranding. Thereafter, we will introduce the mechanism via which we can understand the possibility of old-subject raising in the context of B\&R's system, before returning to the 'VO' grammar in which postverbal linearization of unraised IAs was possible, i.a. owing to the fact that objects were no longer required to raise obligatorily, in the next section.

\subsection{Subject positions in $O V O E$}

In trying to understand how the facts discussed in section 2 are to be accounted for, we will begin by considering the vP-raising mode of EPP-satisfaction. The first point to note here is that the raised $\mathrm{vP}$ contains the subject. In simple cases like the unmodified transitive structures in (19) and (20), vP-raising will result in a structure which is perfectly compatible with the OE data in which a new subject surfaces «low» within the vP-external domain: although it does not typically occupy Spec-

15. There would be cases where it was impossible to tell whether a piedpiping or a stranding EPPsatisfaction mechanism had been employed - in unmodified clauses containing just a subject and verb, for example. 
TP independently, it is nevertheless located within this specifier. As such, it seems possible to retain the generalisation that a subject located within Spec-TP will be interpreted as expressing new (including no longer salient/accessible) information. Additionally, we may be able to understand why this should be the interpretation assigned to subjects in this position: building on i.a. Heim (1982), Diesing (1992) and Uriagereka (1995)'s proposal that elements located within the thematic ${ }^{16}$ (as opposed to TP) domain should be associated with an existential/weak interpretation (interpretations which correlate quite naturally with «novelty»), we can see that the new subject interpretation is to be expected for elements located in Spec-TP if it is the case that these have not in fact raised out of vP, i.e. if $\mathrm{vP}$ as a whole is located in Spec-TP.

As we saw in the preceding section, the EPP requirement on $\mathrm{T}$ in $\mathrm{OE}$ may, of course, also be met by DP-raising out of the vP-domain, so the logic of the above argument may not seem entirely convincing. Assuming as is often done that earlier, more highly inflected stages of OE were more rigidly OV, i.e. required more consistent vP-raising or possibly even absolutely consistent vP-raising, as in a (16c)-type system, we, however, have the possibility of understanding why Spec-TP should have come to be a position associated with new subjects. While vP-raising dominated, the association with newness was unavoidable for the reason just given - the domain of existential/weak interpretation occupied this position. When DP-raising became an option (and, recall, some cases of vP-raising would have been surface-identical to cases of DP-raising), continuing to interpret this position as one associated with new subjects, as the previous generation had done, clearly represents the most natural analysis available to acquirers, who are generally viewed as «conservative» (cf. i.a. Yang 2002 and Niyogi 2006 for recent discussion). As such, we argue that B\&R's approach to OE word-order variation facilitates a potentially important insight into the origins of OE's new subject position, Spec-TP.

One point worth noting in connection with vP-raising to Spec-TP is that this includes «low» subjects, i.e. nominatives which seem to be in their first-merged positions (cf. (12) above, for example). That these low subjects would be interpreted as new elements also follows naturally if they have not left vP. Worth noting, however, is the fact that it was clearly also possible for low subjects to undergo optional raising. Consider (24) in this connection:

(24) ... \& seoppan pis hus oppe seo stow pær getimbred wæs ... and since this house or the place there built was '... and since this house (or the place) was built there ...'

[HomS_46_[BlHom_11]: 125.183.1566]

Van Kemenade \& Westergaard (2009:8) observe that it is not always clear whether such raised subjects are to be interpreted as old or new information. In the context

16. For Diesing, this is VP, but in the context of a theory which assumes vP shells, as in the present case, the domain of nuclear scope would be vP. 
of the present analysis, it is in fact to be expected that both interpretations should be available for these subjects. The reason is as follows: $v$, being a phase head, has the possibility of bearing an optional Edge Feature (cf. Chomsky 2007, 2008); where this Edge Feature targets objects, it clearly does so to defocus them (scrambling in modern OV West Germanic retains this property), and therefore we expect it to be able to target IA subjects in exactly the same way. The expectation, then, is that an IA which has undergone raising to the edge of vP will be interpreted as an old subject. This, in turn, means that vP-raising containing raised IAs will result in Spec-TP hosting an old-rather than a new-information subject, as is typically the case; we return to this point below. Wherever the raised vP contains only the IA and the verb, however, it will not be clear whether the IA has simply undergone the obligatory Agree-imposed raising to Spec-vP or whether it has raised to the edge of vP under the influence of an Edge Feature. Under these circumstances, both a new and an old interpretation would be compatible with the structure, since it would be impossible to tell which vP-edge position the IA that undergoes vP-raising to Spec-TP occupies. The same is true where a structure lacks the diagnostics distinguishing new- and old-information subjects: just as with EAs located at the edge of the raised vP, it will be impossible in this case to determine the position of the subject: inside Spec-TP or in the higher subject position, with the result that both new- and old-information status could potentially be assigned to subjects in such strings. One clear prediction does emerge from our proposed analysis, however, and that is that wherever IAs have clearly undergone raising (i.e. where they precede either some vP-internal material [e.g. vP-adverbials and/or indirect objects] or a diagnostic element), they should be interpreted as old subjects. We leave the empirical testing of this prediction for future research. ${ }^{17}$

Let us now turn to the role of the diagnostic elements discussed in section 2.1 and the old-subject position. As soon as these elements became available as discourse-markers in OE, it became possible to systematically distinguish old and new subjects: the former could precede these markers, while the latter could follow. Arguably, then, these elements played a crucial role in establishing the dual subject-position in OE (and later also, as van Kemenade and colleagues argue, in its loss). Furthermore, being speaker-deixis elements (cf. note 3), they also offered a clear signal to acquirers as to where in the clausal domain these two subject positions are located (assuming some version of Cinque's (1999) hierarchy to hold universally): as the diagnostics must be located within the CP-domain, the higher subject position must be within this domain too, whereas the lower one would not need to be. The question that now arises, however, is whether B\&R's system can facilitate any insight into the development of this higher subject position, and also, at a more basic level, whether it would in fact be possible, on this analysis, for vP-internal subjects to raise from within the vP located in Spec-TP to Spec-FP

17. The possibility of contrastive topicalization also needs to be borne in mind here (cf. note 5). As is the case in modern OV Germanic, it appears to have been the case in OE that both subjects and objects could undergo movement to a more peripheral position, above the old subject position, where they were then interpreted as contrastive topics. 
in (7), to the left of IS-sensitive diagnostic elements. We argue that the answer to both questions is yes.

In the context of a vP-raising (i.e. (16c)-type) system, in which subjects raise along with the entire thematic domain, we might expect it to be impossible to draw a syntactic distinction between new and old subjects: as argued previously, if Heim and Diesing (op. cit.) are correct, vP-internal subjects will always receive what is essentially a new interpretation. Assuming the availability of scrambling possibilities, in particular for objects, however, we see that this is in fact only true for EAs; as discussed in the previous paragraph, IAs may scramble to the edge of vP under the influence of an Edge Feature and, in doing so, become interpretable as old-information subjects. Since EAs cannot scramble vP-internally (v's EF cannot target elements first-merged in a specifier of vP; cf. Ko 2005 for detailed motivation), scrambling is not an option available to these elements. ${ }^{18}$ On the assumption that comp-to-spec («roll-up») movement of the type that takes place when vP raises to Spec-TP differs from spec-to-spec («rolling stone») movement in that it does not result in «freezing» (cf. note 7), it is clear that the subject will be available for scrambling from within Spec-TP ${ }^{19}$; more generally, the contents of the vPs raised to Spec-TP need to be «visible» to higher probing heads if we are to understand how V2 and V3 structures featuring an activated TP-external domain were (and, in modern OV Germanic, are) derived. Let us assume, then, that IA-scrambling within the vP domain had an EA counterpart in the higher phasal domain. If the parallel is to be complete, subject scrambling should then result in defocusing, just as its object counterpart does. And if that is so, we have an explanation for why vP-fronting OV OE should have featured two subject positions in the higher phasal domain, a lower one for new subjects and a higher one for old subjects: these simply mirrored what was available for IAs in the lower phasal domain - a case of structural parallelism. Crucially, if OE had not been a vP-raising system which ruled out the possibility of establishing Spec-TP as an old subject position to which old subjects could raise, the system might not have developed in this way.

Let us now consider how the DP-raising mode of EPP-satisfaction in the OV grammar interacts with the proposal that there are two vP-external subject positions. Recall that B\&R assume DP-raising to Spec-TP to be an alternative to vP-piedpiping, which may initially have been the only available mode of EPP-satisfaction and would therefore instantiate the older of the two options. If there are no constraints

18. Importantly, the restriction on scrambling from specifiers of phase heads implies that objects, too, must be scrambled from their first-merged position. This is unproblematic if all the probing features of a given phase-head probe simultaneously, with their ordering within the feature-bundle (cf. Müller 2009, 2010) (cf. also note 8 on the potential role of structured feature bundles at $\mathrm{PF}$ ) determining structure-building operations: in these terms, v's $\phi$-Probe would be expected to construct a specifier before v's Edge Feature (see again Müller, op. cit.). Consequently, an object could be extracted to the phase edge from its first-merged position with a distinct copy undergoing Agree-driven movement to the innermost specifier; as Agree takes place in situ, the scrambled object will bear valued $\phi$-features, just like the Agree-moved copy. The only remaining challenge, then, is accounting for the fact that only the scrambled copy is spelled out, a question we leave to future research.

19. See Wallenberg (2009) for an attempt at deriving precisely this fact. 
on the DP-raising alternative, we would expect DP-raising to Spec-TP to be possible both for new and old subjects, which can only be correct if old subjects subsequently undergo further movement to the higher subject position. If DP-raising is subject to constraints, however, it could also be the case that only old DP-subjects may undergo DP-raising to Spec-TP (and then onward from there), with vP-raising applying consistently for structures containing new subjects. ${ }^{20}$

There would appear to be one context where the choice between the two alternatives matters. Consider again structures of the sort presented in (11), repeated here as $(25 \mathrm{a})$, in which both the high and the low subject positions are occupied by co-referring material, and also structures like (25b), in which two conjuncts of a co-ordination structure are seemingly distributed across the same two subject positions:

(25) a. Ond mid by he ða se geonga apeling ana pær pa gyt and with that he then the.DEM young prince alone there then still sæt

sat

'And as the young prince still sat there alone...'

[Bede 2: 9.130.20.1246]

b. ... pa se Wisdom pa \& seo Gesceadwisnes pis leoð asungen when the Wisdom then and the Reason this song sung hæfdon, pa ongan he eft sprecan had then began he again speak.INF

'...when Wisdom and Reason, then, had sung this song, then he began to speak again.'

[Bo: 3.9.15.106]

As indicated in section 2, (11)/(25a)-type OV structures occurred in contexts where the writer refers to a previously mentioned, but no longer accessible referent. As such, the pronoun, which appears to be located in Spec-FP, can be thought of as signalling the familiar nature of the referent, while the full DP following the IS-sensitive diagnostic points to the contextual non-salience of the same referent. Assuming for the moment that he se geonga apeling originates as a single constituent (we return to this matter directly in section 4.3), these structures can, in terms of the second scenario outlined above, readily be understood as having involved obligatory vP-raising to Spec-TP, whereafter the pronominal scrambles to Spec-FP.

20. Crucially, both of these alternatives entail an obligatory EPP. Since optional movement operations necessarily entail interpretive effects (cf. Biberauer \& Richards 2006 for detailed discussion), it is not feasible to think of B\&R's optional piedpiping system as entailing an optional EPP on T, at least where $\mathrm{OE}$ is concerned. As we have seen, vP-raising necessarily maintains the interpretive status quo by virtue of the fact that it is a «roll-up» operation which does not alter the positioning of any of the thematic elements; as such, it is not the type of movement that could give rise to the required interpretive effect. We therefore leave aside the possibility that an $\mathrm{OE}$ acquirer would have postulated a system in which vP- and DP-raising were EPP-satisfaction alternatives in an optional EPP system. 
On the double DP-raising option, by contrast, we are faced with an intractable problem: if the entire complex DP raises to Spec-TP in the first instance, we would not expect it to be possible subsequently to extract and raise the pronominal to SpecFP as this would amount to a Condition on Extraction Domains (CED) violation (cf. Huang 1982); in the terms we have used elsewhere in this paper, this would be another case of spec-to-spec raising resulting in freezing. If they also represent movement-derived structures, the same objection holds in the case of first-conjunct raising structures like (25b) (we leave aside here the non-trivial question of how co-ordination splitting of this type is formally licensed). Importantly, structures of this type never pose a problem in the context of a vP-raising (i.e. (16c)-type) system or where the vP-raising option is taken. As they do appear to constrain the application of DP-raising, we conclude that DP-raising seems to have been at least partially restricted during the OE period, being impossible in (25)-type «stranding» structures.

Having considered how B\&R's vP- and DP-raising system interacts with the IS-sensitivity of the OE system, we now turn our attention to the question of how IS-driven movement out of Spec-TP can be understood in the context of an Agreebased system such as that assumed by B\&R.

\subsection{Accounting for IS-driven subject movement}

If $\mathrm{B} \& \mathrm{R}$ 's approach to OE word-order variation and subject positions is to hold up, the question of how the probing heads ( $\mathrm{T}$ and $\mathrm{F}$, in our case) are able to «see» the subjects that they ultimately raise has to be answered. Recall that Goals must be active, i.e. bear unvalued features, if they are to be visible to a Probe. In the standard subject-Agreement case outlined by B\&R, subject-DPs will be visible to probing $\mathrm{T}$ by virtue of the fact that their Case feature will not be valued. Once $\mathrm{T}$ has probed the subject DP and valued its Case feature, however, it might be expected to be inactive and therefore invisible for further probing. How, then, does F manage to probe and subsequently raise old subjects?

To account for this fact, we build on Aboh's (2010) argument that the specifications of the elements in a Numeration include relevant discourse specifications, proposing that old subject DPs (and old DPs more generally; the same logic extends to old objects that undergo scrambling in West Germanic) in IS-sensitive systems of the OE type are structurally more complex than new subjects (see section 5.4 for discussion indicating that this need not universally be the case). Specifically, we propose to extend Zeller's (2008) insight regarding the IS-related role of subjectmarking in Zulu. For Zeller, this marking signals «anti-focus», i.e. old information (cf. Kramer 2010 for a strikingly parallel interpretation of object marking in Amharic). Importantly, its appearance is restricted to cases in which a subject DP has undergone raising to Spec-TP, which is a topic (i.e. old-information) position in Bantu. Consider (26) in this connection: 
(26) a. Aba-fana ba- ya- cul- a

(data from Buell 2006: 19)

II- boy SMII-DIS-sing-FV ${ }^{21}$

'The boys are singing.'

b. $\mathrm{Ku}$ - cul- a aba-fana

XVII-EXPL-sing-FV II- boy

(data from Buell 2006: 23)

'The boys are singing.'

To account for this discrepancy, Zeller proposes a «big DP» analysis of old DPs, in terms of which their structure is as given in (27) (cf. i.a. Kayne 1994, Uriagereka 1995, Cecchetto 1999, Boeckx 2003 for other «big DP» analyses)

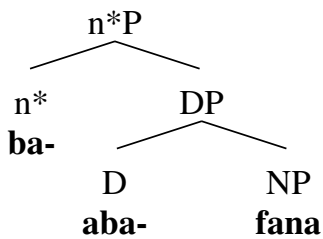

According to Zeller, then, subject agreement markers in Zulu are pronominal clitics, a type of D-head which he specifically classifies as $\mathrm{n}^{*}$ (parallel to $\mathrm{v}^{*}$, but, crucially, viewed as the higher nominal phase-head, following Chomsky 2004) for reasons that need not specifically concern us here (but see Zeller 2008: section 3 for discussion). ${ }^{22}$ That $\mathrm{n}$ * should be a pronominal clitic, which therefore effectively doubles the subject DP is important, however, since it allows us to understand Zulu subject agreement as a phenomenon which fits into the wider clitic-doubling picture: as observed by Kallulli (2000), clitic-doubling is not possible in the presence of focused elements; the absence of subject agreement in structures like (26b), where the postverbal subject is necessarily focused therefore follows.

What unvalued features render $n *$ visible, however? Zeller suggests that this head is associated with a [-Focus] feature, which would not resolve our activity question since [-Focus] is already a valued feature. For both Zulu and OE, it could possibly be an extra grammatical gender feature, [uGender] as gender is morphosyntactically active in these languages (cf. Carstens 2010, 2011 on the features involved in keeping Bantu DPs «active»/«probable»). It could potentially also be an extra [Person] feature, [uPerson] (cf. Richards 2008 who proposes that the pres-

21. The numerals in the glosses signify the numbers conventionally assigned to the noun classes to which the nouns in the examples belong; SM indicates the subject agreement marker; DIS marks the disjoint, as opposed to conjoint, verb form (cf. van der Wal 2008: chapter 5 for detailed discussion); and $F V$ refers to the Final Vowel associated with Bantu verb-forms.

22. For Zeller, then, the traditional subject agreement marker associated with SM-elements is in fact misleading, as the «agreement» is in fact an IS-sensitive clitic rather than agreement proper (cf. Zwicky \& Pullum 1983 for diagnostics distinguishing these two types of element). It may in fact be the case that «subject/object agreement» markers in African languages more generally have been misclassified, a possibility reinforced by recent work such as that of Kramer (2010), who offers a thorough motivation for a pronominal clitic analysis of Amharic «object agreement». 
ence/absence of [Person] correlates with high- vs low-prominence interpretations of various types at LF; the key point here, as in Biberauer 2011, is simply that IS-related formal features need not necessarily be a distinct class from the set of morphosyntactic features generally thought to drive «core» syntactic operations relating to «basic» subject-object syntax). Pending more detailed consideration of this question, let us adopt the [uGender] perspective here as this feature was clearly formalized in OE, and allow for reanalysis in terms of which this feature was gradually replaced by [uPerson] as the evidence for grammatical gender became less robust.

The proposal is that the «extra» [uGender/uPerson] «shell» will render both $\mathrm{n}^{*}$ and the associate DP visible to higher probes. The head and complement of $\mathrm{n} * \mathrm{P}$ can clearly be raised independently of one another: in Zulu (26a), the «antifocus»/old-information $\mathrm{n}^{*}$-head, lexicalising [uGender; Person:3; Number:PL; Gender:II], incorporates with V (assumed to have undergone movement to T) ${ }^{23}$, while the old-information subject itself undergoes raising to Spec-TP; in (26b), only incorporation of expletive (in our terms, new-information-marking) $\mathrm{n}^{*}$, lexicalising [uGender; Person:3; Number:SG; Gender:XVII], takes place, with the associated DP remaining in Spec-vP. This suggests that $n^{*}$ and DP should, in principle, be able to be probed by separate heads. In the case of OE, for example, T may probe $\mathrm{n}^{*}$ for $\phi$-features, raising either the entire $\mathrm{n} * \mathrm{P}$ (DP-raising) or the containing $\mathrm{vP}$ (vP-raising), and a higher head, likewise associated with a $\phi$-Probe, may then probe the still-active DP, raising it to Spec-FP.

This type of analysis would seem extendable to clitic-doubling structures more generally (cf. Kallulli's (2000) observation again), and we might go even further by suggesting that old-information DPs are in fact always «big DPs» featuring a pronominal head of some kind which is either absent in new-information DPs or, possibly as in (26b), represented by an expletive pronominal element (cf. the effect that expletives have of facilitating all-rhematic, i.e. all new-information, structures, a point to which we return in section 5.4). Crucially, since the optional movement-triggering (EPP-)feature on the $\phi$-Probe triggering old-subject raising into the C-domain requires an active Goal, we will only expect its presence to be licensed where its c-command domain contains an appropriate active DP Goal: these conditions are not met when Spec-vP is occupied by a DP lacking the «big $\mathrm{DP} »$ structure/ $\mathrm{n} * \mathrm{P}$ layer of old DPs (as this DP will already have been probed by $\mathrm{T}$, which renders it inactive), nor where spec-vP is occupied by an expletive element (as for full DPs, expletives will be inactive following probing by T). If the «big DP» approach to old DPs outlined in this section is on the right track, we may, in a sense, think of (relevant types of) pronominal elements as much more «all-purpose» old-information markers than is generally thought, and it may not be necessary at

23. The incorporation that takes place here seems amenable to analysis in terms of Roberts's (2010) Defective Goal approach to Agree. The key property of this type of Agree is that it involves a Probe whose features are a superset of those encoded by the Goal, with the result that Agree is said to result in the features of the Goal being spelled out at the Probe site without the mediation of an EPP-feature/movement diacritic. See Roberts (2010) for the details. 
all to postulate a special [topic]/[-focus] feature in syntax. We leave this speculation to future research. For present purposes, we will assume that Zeller's proposal facilitates the insight required to understand how it is possible for an old subject-DP to remain active if it is to be probed by more than one Probe.

Let us now briefly consider in a little more detail how this proposal allows us to understand the OE facts. Assuming old subject-DPs to be «big DPs», we would expect the following: T's $\phi$-Probe probes $n^{*}$, which is active by virtue of its [uGender/uPerson] feature, but fails to encounter further valued features on $\mathrm{n}^{*}$ and so probes further to value its [uPerson] and [uNumber] features, valuing DP's [Case]-feature in the process. As the old-information $n^{*}$ is not phonologically realised, the child has no evidence of the Agreed-with DP moving independently of its IS-related «shell», with the result that it is plausible to assume that the grammar that is postulated will entail entire old-subject $n *$ Ps undergoing raising to Spec-TP. In a vP-piedpiping grammar, however, this $\mathrm{n} * \mathrm{P}$ may also undergo raising as part of $\mathrm{vP}$. Following vP-piedpiping, $\mathrm{n} * \mathrm{P}$ remains visible, owing to the [uGender/uPerson] feature on $\mathrm{n}^{*}$, which therefore cannot be spelled-out in the way that DP can, following valuation of the latter's [Case] feature. ${ }^{24}$ The $\phi$-Probe on F can therefore probe $\mathrm{n}^{*}$ and the movement trigger (EPP-feature) associated with this Probe will raise $\mathrm{n} * \mathrm{P}$ as a whole: following Roberts (2010), incorporation will not be possible in this case as it is always ruled out where a head bears an obligatory EPP-feature (Zulu $\mathrm{T}$, note, does not). In this way, then, we can account for old subject-DP raising in OE. As new subjects lack the $\mathrm{n} *$-layer, they will not be visible for probing by a higher head, accounting for the asymmetry we see in OE (and also in other systems exhibiting an IS-sensitive subject asymmetry of the type we are concerned with here). Since OE T bears an obligatory EPP-feature, new subjects will, however, raise into Spec-TP as part of $\mathrm{vP}$, unlike what we see in Zulu (26).

With this theoretical background in place, we also have the possibility of understanding (25a)-type structures in which both subject positions appear to be filled, with a pronoun filling the higher position. We propose that these structures feature a complex nominal, consisting of a parallel-merged (i.e. adjoined) fully-specified pronoun and an appositive DP; essentially, the proposal is that (25a)-type structures involve what van Riemdijk (1998) refers to as restrictive appositives. The structure of the fully-specified pronoun is of particular importance here: since we may think of apposition as a form of modification, it seems correct to propose that the pronoun in question must be a strong pronoun in the sense of Cardinaletti \& Starke (1999); furthermore, since independent pronouns are old-information elements par excellence (although they can, of course, be focused in cases where salience is a consideration), we adopt the view that their structure always includes the $\mathrm{n}^{*}$-layer associated with old-DPs generally (thus also accounting for the fact

24. As for clausal «satellites» (broadly, specifiers) more generally, we assume spell-out in this case to take the form of atomisation, i.e. reduction to a structure which Narrow Syntax «sees» as a head whose internal features are no longer accessible (cf. Nunes \& Uriagereka 2000 for discussion). Radical spellout (cf. note 9) only applies to the complement of non-defective phase-heads associated with the main spine being generated (i.e. VP and TP in the case we are concerned with here, namely the clause). 
that pronouns systematically undergo raising to the higher subject position ${ }^{25}$. The nominal corresponding to the restrictive-appositive subject in (25a) will therefore take approximately the structure given in (28):

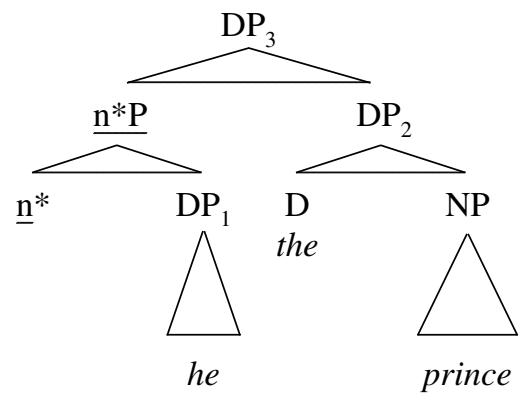

For cases like (25a), then, T's $\phi$-Probe will probe the restrictive-appositive-containing $\mathrm{DP}_{3}$, Agreeing with the full $\phi$-set associated with the complex DP. Assuming these features to be visible at the maximal projection $\left(\mathrm{DP}_{3}\right)$, we would expect both pronominal $\mathrm{DP}_{1}$ and $\mathrm{DP}_{2}$ to have their Case-features valued as a result of this Agree operation; if appositive structures do not involve «normal» projection (which we might assume also to involve percolation), at least the full $\phi$-set associated with $\mathrm{DP}_{2}$ should be probable by $\mathrm{T}$, with the result that at least this DP's Case-features are valued by T. For our purposes, the specifics of this issue do not matter. What is clear is that $\mathrm{T}$ will be able to value at least $\mathrm{DP}_{2}$ 's Case-feature, with the result that it, at the very least, will be spelled out, as outlined above. T's EPP-feature then triggers vP-piedpiping, as usual, whereafter $\mathrm{F}$ will probe $\mathrm{n} * \mathrm{P}$ located within Spec-TP and visible by virtue of the [uGender/uPerson] feature of its $n^{*}$-head. As $\mathrm{F}$ is EPP-bearing, the Agreed-with $\mathrm{n} * \mathrm{P}$ undergoes raising to Spec-FP, giving (25a). If (25b)-type co-ordination structures can be given a similar complex nominal analysis to (25a)-type structures, the same is true for these structures. The existence of clear OV structures featuring subjects of this type should therefore be viewed as a strong argument in favour of B\&R's vP-raising approach to the OV structures that surface in OE.

\subsection{Interim Summary}

In this section, we have established that B\&R's vP-raising approach to OV OE is indeed compatible with van Kemenade and colleagues' identification of the IS-sensitive subject positions, Spec-TP and Spec-FP. Although Spec-TP for B\&R is not a designated subject position, instead being the landing-site for $\mathrm{vP}$, we see

25. That generic pronouns typically fail to raise also follows naturally on the present account since we would not expect generic pronouns, given their non-specific status, to be associated with $n^{*}$ except under circumstances where a generic subject is already contextually salient. By virtue of its reflexive speaker-referring property, impersonal man may constitute a generic element that is intrinsically salient in the relevant context (cf. the discussion on p.7). 
that this approach allows us to understand why it should be new subjects that are found in this position: following Heim, Diesing and others mentioned in section 4.2., vP-internal subjects are necessarily interpreted as new, with the result that the subjects located within the raised vP in Spec-TP can only be interpreted as such. ${ }^{26}$ From within Spec-TP, it is, however, possible for old subjects to undergo scrambling to Spec-FP since nothing prevents elements within a «rolled-up»vP from undergoing further movement.

We have also presented a formal analysis of how these movements can be understood in the context of a Probe-Goal system like Chomsky (2000 et seq.), proposing that old subjects (and old DPs more generally) differ from new subjects in structural terms. Specifically, old subjects are said to feature an «extra» pronominal shell $\left(\mathrm{n}^{*}\right)$. This additional structure, which seems to be well-motivated if we consider languages like Zulu, which exhibit overt morphological differences between structures containing old and new elements, allows old elements to remain active and thus visible to Probes in a way that is not possible for structurally simpler elements. $^{27}$

In the following section, we will briefly consider how B\&R's approach accounts for the positioning of subjects in VO structures attested in OE.

\subsection{Subject positions in $\mathrm{VO} O \mathrm{OE}$}

We begin our discussion by considering the derivations which give rise to the subject-placement facts observed by van Kemenade and colleagues in main clauses. Wherever these structures feature an initial non-subject, subject-positioning can be understood in the way described in sections 4.2 and 4.3 above: new subjects are located in Spec-TP, either as part of vP or by virtue of having undergone independent raising, while old subject-DPs have undergone further raising from within a raised vP, with the additional structure associated with these elements facilitating the additional probing operation initiated by the CP-internal F-head whose spec serves as their landing site. These are the positions respectively occupied by new and old subjects in non-subject-initial V2 and V3 clauses. We maintain the same assumptions for subjectinitial V2 clauses, hypothesising that new subjects in main clauses systematically fail to raise from Spec-TP in the absence of special focus properties (e.g. contrastive focus), just as they fail to do so in subordinate clauses; in the absence of an alterna-

26. Scrambled (i.e. defocused/old) IAs are clearly an exception to this generalisation. We leave this case aside for the moment, but return to the question of the role of IAs in determining the development of the English subject system in section 5.3.

27. It may, of course, also allow us to understand why $\mathrm{D}$ (iscourse)-linked elements should exhibit «special» behaviour in various contexts, including, for example, permitting extraction under circumstances that non-D-linked elements do not (cf. Pesetsky 1987, 2000 for discussion). If the extra pronominal $n *$-structure postulated here is associated with an Edge Feature, for example, we can see that material within $n * P$ could be raised to its edge, prior to the merger of $n * P$ with the main clausal spine, with the result that this raised DP-material would remain visible for further movement under the influence of higher EPP-/Edge Feature-bearing Probes. These speculations, too, we leave to future research. 
tive first-position element, an expletive fills Spec-CP. ${ }^{28}$ If we are correct in viewing Spec-FP as a position within the C-domain, the initial placement of old subject-DPs can be understood without postulating any further movement.

Let us now turn to non-matrix VO-structures. As already noted in section 2.3.1, structures in which $\mathrm{V}$ precedes $\mathrm{O}$ are typically biclausal, involving restructuring predicates. In the case of SAuxVO structures, $\mathrm{O}$ fails to raise into the main clause as a consequence of one of two factors: either it has undergone raising to (internal) Spec-vP, but then not been piedpiped into Spec-TP as a consequence of the subject DP-raising option having been taken to satisfy T's EPP-requirements (with V in non-finite T; see note 11), or it has failed to undergo any raising by virtue of its not being a negative or old-information DP (cf. section 3.3 above).

Adapting B\&R's basic proposal as outlined in section 3.2 and foreshadowing their $(2006,2008)$ analysis of ME OV ordering, we propose that the non-raising option can be understood as the consequence of a reanalysis of the Probe associated with v: we propose that, while earlier (in part at least, unattested) OE v bore a $\phi$-related EPP-feature which systematically triggered either VP-piedpiping or object DP-raising, the EPP-feature on later $\mathrm{OE} \mathrm{v}$ was associated specifically with v's operator features ${ }^{29}$, with valuation of Op as Neg systematically triggering negative object raising (cf. Biberauer \& Roberts 2011 for more detailed discussion of the probing relations involved in structures containing negative indefinites). The obligatory EPP-feature on v thus became more specialised, as indicated in (29), and the possibility of EPP-less v (i.e. head-initial v) was introduced:

$$
\mathrm{EPP}_{\mathrm{D}} \rightarrow \mathrm{EPP}_{\mathrm{D}[+\mathrm{neg}]}
$$

Additionally, acquirers of later OE retained the possibility of optionally raising non-negative objects for information-structural reasons, specifically, defocusing (cf. scrambling in modern West Germanic). This optional object-raising operation, which was presumably always a separate operation, even in earlier OE (cf. again modern West Germanic, where this is also the case), was triggered by a distinct movement trigger - the Edge Feature associated with $v$ by virtue of its status as a phase head (cf. again section 4.2). Importantly for the present discussion, these changes led to a rise in the number of $\mathrm{VO}$ orders available in $\mathrm{OE}$, a crucial development considering later word-order developments in the language. Specifically, the loss of systematic object-raising meant that SVO and SAuxVO orders could be generated by the grammar in even more ways than were already available to

28. As we will see in section 5.4, OE expletives are best thought of as discourse-sensitive elements compensating for the absence of a suitable topic constituent to fill a preverbal specifier within the CP-domain where a focus or other continuative topic element is also unavailable, and not as the subject-elements they are generally thought to be today (cf. also Biberauer 2010, in prep. a for discussion).

29. On the assumption that a head's $\phi$-features are lower within a structured feature-bundle than its operator features - thus effectively paralleling the structure that is commonly assumed for clausal and nominal projections (cf. the T- vs C- and the D vs Q-domains) - this diachronic change can be viewed as another case of «upwards reanalysis» (cf. Roberts \& Roussou 2003). 
the systematically object-raising 'OV grammar' (which, of course, also entails V2 in the general sense of finite-verb raising into the CP-domain); and, additionally, SVAuxO («Stylistic Fronting»/SF with object) orders also became generable.

As noted in section 3.3 above, SVAuxO ordering is not one that can be generated by a consistently or optionally VP-piedpiping OV grammar (SF where objects and other non-verbal VP-related material is absent, by contrast, is, giving SVAux orders). In non-object-raising structures (i.e. those involving EPP- and Edge Feature-less v), however, this order would have resulted where both subordinate and main-clause T's EPP-requirement was satisfied via vP-piedpiping: wherever objects failed to raise, $\mathrm{vP}$ would contain only the raised $\mathrm{V}$ (cf. (14ii) above) and the subject, thus giving rise to surface SVAuxO, as illustrated in (24) above. ${ }^{30}$ Given that negative objects, in accordance with (29), necessarily underwent raising out of VP, either independently or as part of remnant VP, we predict that SVAuxO structures featuring negative objects should be absent from the OE data, a prediction which awaits empirical testing (for a speculation as to why $\mathrm{SVO}_{\mathrm{Neg}}$ Aux structures are also unattested, see note 13). For our discussion of OE subject positions, however, the importance of the existence of SVAuxO structures lies in the fact that these structures would have served as a clear signal to OE acquirers that the system they were acquiring involved vP-raising and not just subject DP-raising, and also that the system did not categorically require object-raising (a fact which meant that already structurally ambiguous strings like SVO- and SAuxVO-orders could in fact, alongside the other options already mentioned, also be analysed as lacking object movement, rendering them many-ways ambiguous in a way that we might expect to be significant in language-acquisition and change scenarios) ${ }^{31} \mathrm{On}$ a vP-raising analysis - which would, of course, also allow them to generate the $\mathrm{OV}$-structures discussed in the preceding section, and the VO-structures mentioned there and also earlier in this section - the subject and V undergo raising to Spec-TP as a single constituent, whereafter old subjects undergo further raising to Spec-FP, in the manner suggested in the previous section (as observed in note 31, Aux might also undergo further raising, thus making it impossible for acquirers to establish for sure whether SAuxVO orders were derived via independent subject DP-raising or SF-style objectless vP-raising; an important ambiguity to which we will return in section 5.1 below). If Spec-TP were to be analysed as a designated subject position (associated specifically and exclusively with new subjects), by contrast, more complex assumptions would have to be made about the structure of SF-strings. As we will show in the following section, we would also not be able to understand why the loss of SF-orders coincided with the regularisation of what we today think of as «canonical» subject properties, including overt expletive realisation. SF, then,

30. As Aux would have undergone further movement in main clauses, it is clear that this «Stylistic Fronting» derivation would not always have been detectable from surface facts; in subordinate clauses, however, its occurrence would be clear (cf. Biberauer \& Roberts 2006 for further discussion and references).

31. This, of course, assumes that SF-structures were sufficiently robustly attested in the PLD, and not restricted to a particular register, as appears to be the case in modern languages exhibiting this structure. 
provides another argument for viewing OE Spec-TP not as a designated subject position, but rather as a position which could host either vP or subject DPs, depending on the mechanism by which T's EPP-requirements were satisfied.

What we have seen in this section, then, is that Spec-TP in OE VO-structures would have exhibited largely the same behaviour as Spec-TP in OE OV-structures: like the latter, it could host a raised $\mathrm{vP}$ or a raised subject-DP, with many attested orders being superficially ambiguous as to their precise underlying structure and thus serving as a potential springboard for future changes. Unlike raised $\mathrm{vPs}$ in OV-structures, however, those in VO-structures did not need to contain the object, a state of affairs which we will see is significant in understanding the further development of English subject positions. As far as the IS properties of subject positions in OE VO-structures is concerned, we can also see that these structures would not have undermined acquirers' OV-based hypothesis that two IS-sensitive subject locations should be identified: Spec-TP for new subject-containing verbal projections or new subjects alone, and Spec-FP for old subjects. Taken together, however, it is clear that the range of word-order options available in OE would have entailed a significant amount of ambiguity as to the precise location of subject elements, particularly in unmodified sentences featuring just the «basic» subject and verb components, but also in many of those additionally featuring objects and auxiliaries. Against this background, the existence of the diagnostic elements identified by van Kemenade and colleagues thus proves crucial, a point to which we will return in section 5 .

\subsection{Concluding summary}

The focus of this section has been on showing how the IS-sensitive subject positions identified by van Kemenade and colleagues can be understood in terms of a formal system which initially aimed to account for the word-order variations that were possible in OE, that of B\&R. We have argued that approaching SpecTP not as a designated subject position specifically associated with new subjects, but, instead, as a position which initially hosted a raised (OV) vP including the, in subordinate clauses, mostly string-initial subject allows us to understand why Spec-TP should have come to be associated with new subjects: vP-internal subjects perhaps universally receive a focused or non-specific interpretation of the sort that is very compatible with new material. In a system where vP-raising alternates with DP-raising, then, the natural expectation is for subject-DPs raised to Spec-TP to resemble those raised as part of $\mathrm{vP}$ in receiving a new-information interpretation. Similarly, if vP-raising at one point constituted the only means of satisfying T's EPP-requirement, further movement presents itself as a plausible means via which the old-information status of subjects might be signalled explicitly; and, in OE, such movement would already have had an analogue in the object-domain, assuming object-scrambling to be an integral component of OV systems, at least of the nominative-accusative type (cf. also the behaviour of non-Germanic nominative-accusative OV languages like Turkish, Persian, etc. in this connection). 
In addition to providing a formal account of the nature and potential origins of the IS-sensitive OE subject system, we have also offered a novel formal account of the mechanics of new- vs old-subject raising. In this connection, the relevance of the attested word-order variation in OE received special attention, with the latter ultimately leading us to the conclusion that the diversity of the variation to which acquirers would have been exposed - assuming all of the orders discussed to be robustly attested in the PLD, of course - rendered the role of van Kemenade and colleagues' diagnostics absolutely essential in maintaining the IS-sensitive system that can clearly be discerned in the attested OE corpus. The following section considers the consequences of the loss of some of the OE word-order variation and also of its diagnostic elements for this IS-sensitive system and its subsequent development.

\section{The further development of subject positions in the history of English}

\subsection{Subject positions in Middle English: the effects of derivational opacity}

According to Biberauer \& Roberts (2008), the loss of VP-piedpiping led to a «cascade» of parametric changes. In basic terms, these can be schematized as in (30) (note that $O$ signifies objects of the type that could undergo movement rather than objects across-the-board, i.e. negative and old objects, as discussed in sections 3.3 and 4.5 above):

(30) Changes in the satisfaction of v's movement trigger (EPP-feature):

Reanalysis I:

a) Early ME - loss of the VP piedpiping mode of EPP-satisfaction $\left[_{v \mathrm{P}}\left[{ }_{\mathrm{VP}}(\mathrm{V}) \mathrm{O}\right] \mathrm{V}+v(\mathbb{V P})\right] \rightarrow\left[_{v \mathrm{P}} \mathrm{O} \mathrm{V}+v\left[{ }_{\mathrm{VPP}}(\mathbb{V})(\mathrm{O})\right]\right]$

b. «knock-on» changes in the satisfaction of T's movement trigger (EPP-feature)

Reanalysis II:

Late $\mathrm{ME}$, around 1450 - loss of the $v \mathrm{P}$ piedpiping mode of satisfaction

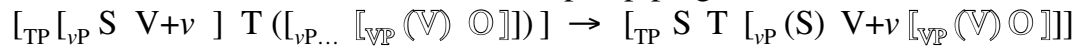

These reanalyses can be viewed as a «cascade» for the following reasons. Postulating piedpiping options alongside stranding ones is costly in acquisitional terms as it involves postulating a «bigger» grammar, and so requires robust input (cf. Biberauer \& Roberts 2009). We would therefore expect acquirers to postulate optional piedpiping grammars of the (14d)-type only where the input justifying this postulation is readily available to acquirers. Various empirical considerations, however, undermined the saliency of the piedpiping options, empirical considerations which multiplied throughout the OE period. These crucially include the increase in «leaking» possibilities (cf. (19c,d) and (23) above), which included structures in which objects could surface postverbally, and the fact that auxiliary-less V2 structures typically obscured what had moved (cf. (31) below). All of this undermined the evidence for VP-piedpiping, leading to Reanalysis I. 
(31) Đa sone pæræfter sende se kyng hise write ofer eal Englalande then soon thereafter sent the king his writ over all England

'Then soon after that, the king sent his writ to the whole of England.'

[CMPETERB, 42.40]

As (31) shows, it is impossible, in the absence of a lexical verb in the v/VP domain, to determine whether only the object or the object plus the VP-internal PP has undergone movement. Possible analyses of (31) therefore include:

(32) a. VP piedpiping in an auxiliary-less V2 clause:

$\left[_{\mathrm{CP}} \mathrm{XP} \mathrm{V}+v+\mathrm{T}+\mathrm{C}\left[_{\mathrm{TP}} \operatorname{Subj}(\mathrm{V}+v+\mathrm{T})\left[_{v \mathrm{P}} \operatorname{Subj}\left[_{\mathrm{VP}} \mathrm{Obj} \mathrm{PP}(\mathrm{V})\right](\mathrm{V}+v)\right]\right]\right](\mathrm{VP})$

b. VP-stranding in an auxiliary-less V2 clause:

$\left[_{\mathrm{CP}} \mathrm{XP} \mathrm{V}+v+\mathrm{T}+\mathrm{C}\left[_{\mathrm{TP}} \operatorname{Subj}(\mathrm{V}+v+\mathrm{T})\left[_{v \mathrm{P}} \operatorname{Subj}\left[_{\mathrm{VP}} \mathrm{Obj}(\mathrm{V})\right](\mathrm{V}+v)\right]\right]\right] \mathrm{PP}(\mathrm{V})$ (Obj)

Following the loss of VP-raising in the vP-domain, object-raising targeting specific object-types (old and negative, as discussed in sections 3.3 and 4.5) remained, ME having become a (14b)-type system. Even for structures containing objects that did still front, though, it would not always have been superficially clear that objectmovement had taken place. Auxiliary-less V2 clauses like (32) and Verb Projection Raising (VPR) structures like (33) would, for example, obscure this movement in the manner schematically indicated (cf. Taylor \& Pintzuk, this volume, for detailed discussion of relevant data):

(32) In pus many maners touches pe ymage of dremes men in so many ways touches the image of dreams men 'In so many ways, the image of dreams affect men.'

(CMROLLEP, 93.499; Trips 2002: 251)

Possible analyses:

a. object movement has taken place:

$$
\left[_{\mathrm{CP}} \mathrm{XP} \quad \mathrm{V}+v+\mathrm{T}+\mathrm{C}\left[_{\mathrm{TP}} \mathrm{S}(\mathrm{V}+v+\mathrm{T}) \quad\left[_{v \mathrm{P}} \mathrm{O}(\mathrm{V}+v)\left[_{\mathrm{VP}}(\mathrm{V})(\mathrm{O})\right]\right]\right]\right]
$$

b. object movement hasn't taken place:

$$
\left[\left[_{\mathrm{CP}} \mathrm{XP} \quad \mathrm{V}+v+\mathrm{T}+\mathrm{C}\left[_{\mathrm{TP}} \mathrm{S}(\mathrm{V}+v+\mathrm{T}) \quad\left[_{v \mathrm{P}}(\mathrm{V}+v)\left[_{\mathrm{VP}}(\mathrm{V}) \mathrm{O}\right]\right]\right]\right]\right.
$$

(33) ... pat \&e mahen ane pine me here that you may alone torture me here

'... that you may only torture me here.'

(St Juliana; Fischer et al. 2000: 161)

Possible analyses (cf. again note 11):

a. object movement has taken place:

$$
\mathrm{V}_{\mathrm{R}}\left[_{\mathrm{TP}} \quad \mathrm{PRO} \quad \mathrm{V}+v+\mathrm{T} \quad\left[_{v \mathrm{P}} \mathrm{O}(\mathrm{V}+v)\left[_{\mathrm{VP}}(\mathrm{V})(\mathrm{O})\right]\right]\right]
$$

b. object movement hasn't taken place:

$$
\mathrm{V}_{\mathrm{R}}\left[_{\mathrm{TP}} \quad \mathrm{PRO} \mathrm{V}+v+\mathrm{T} \quad\left[_{v \mathrm{P}}(\mathrm{V}+v)\left[_{\mathrm{VP}}(\mathrm{V}) \mathrm{O}\right]\right]\right]
$$


Taking the above into account, we can see that, even before object-movement was fully lost in the 14th century, the unclarity as to whether it had or hadn't taken place would have affected acquirers' ability to establish what kind of movement to Spec-TP was required. Consider, for example, the fact that, from the outset, many vP-raising operations could equally have been analysed as DP-raising cases. The auxiliary-less clauses containing only a subject, with or without modification illustrated in (34) are cases in point, as are auxiliary-less V2 clauses, objectless and unmodified VPR structures, and so on:

(34) hwenne preostes of pe world singeð heore messen. when priests of the world sing their masses 'when the priests of the world sing their masses.'

[CMANCRIW, I.62.195]

Possible analyses:
a. $\quad\left[_{\mathrm{TP}}[\right.$ Subj $] \mathrm{T}\left[_{v \mathrm{P}}(\right.$ Subj) V+v $]\left[_{\mathrm{VP}}(\mathrm{V})\right.$ Obj] $\quad--$ DP-raising
b. $\quad\left[_{\mathrm{TP}}\left[{ }_{v \mathrm{P}}\right.\right.$ Subj $\left.\left.\mathrm{V}+v\right] \mathrm{T}\right](v \mathrm{P})\left[{ }_{\mathrm{VP}}(\mathrm{V}) \mathrm{Obj}\right]$
$--\nu$ P-raising

With even object-containing structures not providing reliable evidence for vP- as opposed to DP-raising, the availability of other cues signalling this possibility would have been crucial in order to maintain sufficiently robust input. Stylistic Fronting-structures (SVAuxO) would, as discussed in sections 3.3 and 4.5, have provided one form of appropriate evidence of the need to postulate vP-raising. Further, in light of the discussion of vP- vs DP-raising in relation to complex nominal «stranding» structures like (25), structures of this type would also be expected to signal the need for $\mathrm{vP}$-raising to Spec-TP. In relation to both of these structures, however, one might raise the question of how frequently they would have surfaced in the PLD. Structures that may have surfaced more systematically are expletiveless structures like that in (35a) and unraised passive and unaccusative structures of the kind shown in (35b) and (35c):

(35) a. And in alle the world is no gretter treson ...

'And in all the world there is no great treason ...'

[Prologues, Caxton 12.15]

b. and so were alle pe maidenes martrede for pe loue of God, 'And thus were all the maids martyred for the love of God, ...'

[BRUT3, 44.1329]

c. And in pis tyme were sent writtis porowoute pe lond and in this time were sent writs throughout the country 'And in this time, writs were sent throughout the country.'

[Capgrave Chronicles 213.72] 
The reasoning here is that vP-fronting would account for the absence of overt expletives - which was widespread for clause-internal (i.e. potentially Spec-TPrelated) expletives during the $\mathrm{OE}$ period, before declining during the ME period (cf. Williams 2000 and B\&R for discussion and references) - in that it would not presuppose a designated subject position in Spec-TP that systematically requires filling; instead, vP-raising to Spec-TP would be expected to preclude the need for non-selected (e.g. weather) expletives (cf. Allen 1995 and Williams 2000 on the early establishment of quasi-argumental/«weather» it in the history of English). Clause-internal expletives, then, would only be expected to play a role where the DP-raising mode of EPP-satisfaction was employed. ${ }^{32}$ Similarly, subject-raising would not be necessary in the context of a vP-raising system as vP-raising will always carry either the subject or, where an IA-subject has not undergone raising into the $\mathrm{vP}$ (e.g. by virtue of its being neither old nor negative), as in (35c), a nominal-feature bearing passive participle (cf. Richards \& Biberauer 2005 for discussion of this latter case), to Spec-TP. Previous studies (cf. B\&R and Biberauer \& Roberts 2008 for references) have shown that the frequency of (35)-type structures dropped significantly during the ME period, thus further jeopardising the cue for acquirers to postulate vP-raising. Once the frequency of SF-, (25)-type and (35)-type structures dropped beyond the required level of robust attestation, $B \& R$ propose that acquirers reanalysed their system as a systematically DP-raising one: Reanalysis II, in terms of which Spec-TP became an exclusively subject-related position. ${ }^{33}$ Importantly, then, B\&R's system allows us to understand not only the directionality inherent in the observed «cascade» of word-order changes, but also how it would have led to changes in the subject system.

Here we would, however, like to question whether it is in fact justified to view a single canonical subject position as the end-point of B\&R's «cascade». As we have seen in earlier sections, van Kemenade and colleagues' work on the IS-sensitivity of the earlier English subject system clearly shows that subjects could occupy at least two vP-external positions (leaving aside contrastive topic/focus subjects which might undergo further fronting within the CP-domain). Like the vP-raising possibility considered by B\&R, this IS-sensitive system was undermined by wordorder and other changes taking place in ME. So, for example, this period saw the loss of adverbial diagnostic elements like $p a$ and ponne, which had previously served to mark the boundary between new (rightward) and old (leftward) subjects,

32. Contrary to the standardly held view during the GB period, there appear to be numerous convincing reasons to view subject-related expletives of the PDE type as elements which are initially merged in Spec-vP rather than Spec-TP (cf. i.a. Richards \& Biberauer 2005, Deal 2009 and Biberauer 2010, in prep.a for discussion). As such, we can see that PDE-style expletive-containing structures would involve DP-raising in a manner entirely parallel to what we see in structures containing non-expletive subjects.

33. Worth noting here is that this reanalysis is assumed to give rise to V-to-T raising, an operation which B\&R, unlike the majority of $\mathrm{OE}$ researchers, do not assume to be part of the grammar of OE (cf. Biberauer \& Roberts 2008, 2009, 2010 for detailed discussion). An appealing aspect of B\&R's proposal that OE lacked V-to-T movement is that it brings OE into line with modern-day OV Germanic languages, none of which feature V-to-T movement (cf. Vikner 2005). 
and of OE's V2/V3-alternating grammar, which had served the same function (cf. (2); cf. van Kemenade \& Milicev 2005/forthcoming and van Kemenade \& Westergaard 2009 for discussion and references). Further, the $s e$-demonstrative series (cf. section 2) was lost during the early ME period, so that potential signal as to the grammatical significance of IS-considerations in ME was also not available to acquirers. Taken together, it is clear that these losses would have undermined the relatively clearcut OE distinction between new (Spec-TP) and old (Spec-FP) subject positions schematised in (7). Importantly, this would have aggravated the derivational opacity problem already facing ME acquirers as a consequence of the OV/VO-related changes outlined in this section. The question that now arises is whether the input at the end of the ME period completely undermined the postulation of an IS-sensitive subject system, leading acquirers to postulate the PDE-style canonical subject position assumed by B\&R, or whether remnants of IS-sensitivity led to a different analysis. As the following section will show, there is evidence that B\&R's proposal is not in fact the correct one and that subject-related IS-sensitivity persisted beyond the ME period. Our proposal, then, will be that we can better understand Spec-TP-related developments in ME and beyond if we take OE's IS-sensitive subject system into account.

\subsection{Evidence that Spec-TP in EModE did not yet correspond to the PDE subject position}

Some indications that the modern system was not in place yet at the point at which $\mathrm{B} \& \mathrm{R}$ propose that a canonical subject position arose come from data indicating points of continuity with $\mathrm{OE}$. Consider, for example, evidence of the continued availability of «low» internal-argument (IA) subjects into the early Modern English (EModE) period:

(36) a ... \& pær gen to dæge heofonlic wundor mærsode beoð

(OE) and there still to day heavenly marvels celebrated are ' $\ldots$ and still at the present day heavenly marvels are celebrated there.'

[cobede, Bede_3: 1.156.8.1494]

b. but Kyng Arthure and his men quellede so meny Saxones, but King Arthur and his men killed so many Saxons pat neuer er was seyne sochs a slauzter that never before was seen such a slaughter

[CMBRUT3, 70.2116]

c. Then was redd the deposicon of Sir fferdinando Gorges (EModE) to this effect, 'Then the deposition of Sir F.Gorges was read, to this effect ...'

[ESSEX-E2-H, 9.25]

Similarly, expletive there and $i t$ were still not systematically required during the EModE period: 
(37) a. But let us set her yf please you

(EModE)

'But let us set her, if it please you.'

[BOETHEL-E2-P2, 98.491]

b. for outwardly were left somthing to be wisht

'For outwardly, there was something left to be desired.'

[BOETHEL-E2-P2,44.28]

For B\&R, the establishment of a canonical subject position in Spec-TP during the late ME period leads them to expect subject-raising and expletive usage to be systematic as vP-raising is no longer available to satisfy T's EPP-requirement following the loss of this option.

Also connected to expletives are the Transitive Expletive Constructions (TECs), which were innovated during $\mathrm{ME}$ and then retained into the EModE period:

(38) a. but unethe schal ther any wight mowe seen it or come thereto (ME) but hardly shall there any person be-able to-see it or come thereto

[Chaucer Boece V. Prosa 6. 169-172 / Breivik 1983: 303]

b. pere coupe no man it aquenche wip no craft there could no man it quench with no craft

[Trevisa Higden (Rolls) I. 223 / OED; Tanaka 2000: 480]

(39) a. there can no greater plage inuade a commen wealth there can no greater plague invade a commonwealth

(EModE)

[J. Daus tr. Sleidane's Comm. 155 / OED]

b. there shall no poore neighbour of mine bere no losse ...

there shall no poor neighbour of mine suffer any loss

[More in Four C. Eng. Lett. 12 / OED]

Finally, structures featuring so-called Post-Finite Misagreement (PFM; cf. Grohmann \& Ingham 2009) also persisted:

(40) a. There is gret spies leid here at London

'Many spies are being planted in London'

(ME)

[Paston D 86, 17; Grohmann \& Ingham 2009: 312]

b. This yere after alhalontyde there was proclamations made in London

by the kingis commandement

(EModE)

'This year after All Saints' Day, proclamations were made in London by the King's command.'

[Gough 163 (1469); Grohmann \& Ingham 2009: 313]

c. And on xx day of Janyver was certayne poyntys of armys done (EModE) in Smethefylde

'And on the $20^{\text {th }}$ of January, various feats of arms were accomplished in Smithfield.'

[Greg. 184 (1441); Grohmann \& Ingham 2009: 321] 
All of these possibilities are surprising if we adopt B\&R's proposed analysis of the outcome of the parametric «cascade» observed during the OE and ME periods. By contrast, incorporating the insights of an IS-sensitive approach to the structure of $\mathrm{OE}$ and $\mathrm{ME}$ can allow us to gain further insight into the system that acquirers were left with at the end of the ME period. Specifically, it becomes clear that Spec-TP could not yet have been a position reserved exclusively for subjects, although it is equally clear that retention of a system featuring two IS-sensitive subject positions in the higher clausal domain (Spec-TP and Spec-FP) also would not have been straightforwardly feasible. The following section will briefly outline why this is so.

\subsection{Rethinking Spec-TP in the context of an IS-sensitive analysis of earlier English}

Our proposal is that, at the point at which vP-raising was lost, it was generally unclear to acquirers what kind of position Spec-TP is, i.e. that there was not, at this stage, a single unambiguous direction for the grammar to develop in (contra Biberauer \& Roberts 2008). More specifically, we argue that IS considerations of the type considered here allow us to understand why B\&R's «cascade» of parametric changes (which can be viewed as a type of «drift») ended with the loss of vP-raising to Spec-TP, the nature of Spec-TP not being unambiguously determinable at this point (cf. Biberauer \& van Kemenade 2011 for further discussion). Our central contention is that acquirers at this point would have been uncertain as to whether Spec-TP should be analysed as a generalised subject position or as a different kind of IS-sensitive subject position. Here we highlight some of the reasons for this.

The late ME input would have featured numerous conflicting structures, undermining the acquirer's ability to fix upon a clearly defined analysis of the nature of Spec-TP. These include:

a) evidence from the behaviour of internal argument/IA subjects (passives, unaccusatives, etc.), which, as illustrated in (36c) above, appear to have continued to exhibit salient IS-sensitive behaviour, with new IAs remaining unraised and only given IAs undergoing raising;

b) evidence from TECs - as for (a);

c) the behaviour of «expletive» there, which does not in fact seem to have been part of the lexical inventory of all speakers in its modern guise by the end of the ME period. Instead, the empirical evidence suggests that acquirers may have postulated different analyses of its nature and obligatoriness; and

d) the behaviour of «expletive» it in its various «anticipatory» uses (including itclefts, which only became systematically established during the EModE period - cf. Ball 1991). Since it flags up a following specific or presupposed XP, this expletive clearly represents a lexical item reinforcing the notion that discourseoldness may be formally marked in the grammar.

Our contention is that these factors together left acquirers with various, nondecidable analytical options regarding the nature of Spec-TP. In essence, (a-c) 
represent a corner of the original IS-sensitive subject system that was preserved beyond ME. In some cases, there seems to be a readily available explanation as to why this preservation would have occurred. Consider, for example, the case of unraised IA-subjects. Assuming the correctness of the assumption that is being made here that raising vs non-raising of IA-subjects would have continued to reflect IS-considerations - old IA-subjects raise; new IA-subjects remain in situ, a proposal which would allow us to understand the general prevalence of unraised subjects in «presentational»/«existential» contexts (cf. i.a. Breivik 1983, Ingham 1997, Williams 2000, Tanaka 2000 and Ingham 2001, 2003) - we can see that non-raising as opposed to raising would have become more and more salient as $\mathrm{OV}$ word order was lost during the ME period. This is because unraised new IAs would surface postverbally in VO-structures and thus very unambiguously have failed to raise. Consider again (36b), repeated here as (41):

(41) but Kyng Arthure and his men quellede so meny Saxones, but King Arthur and his men killed so many Saxons pat neuer er was seyne sochs a slauzter that never before was seen such a slaughter

[CMBRUT3, 70.2116]

We argue that the persistent clearly distinct behaviour of new IA subjects during the ME period, even after (many of the) unambiguous cues for the earlier distinctive behavior of given subjects had been lost, in fact allowed ME to remain an IS-sensitive system. The nature of that system changed, however: a subset of new subjects (IAs) became positionally marked, which may have created the impression that Spec-TP could be a position reserved for non-new subjects, thus further undermining Spec-FP's status.

At the same time, however, it appears that a range of IS-sensitive structures centred on old information was on the rise. Thus Ball (1991) shows that the range of IS-sensitive it-cleft structures found in PDE (cf. i.a. Prince 1978 and Lambrecht 2001) were only in the process of becoming established during the late ME and earlier EModE periods, becoming fully entrenched by the late EModE period. Prominent among these structures are so-called informative presupposition itclefts (e.g. It was just last week that Federer beat Djokovic). In structures of this type, the content expressed in the relative clause is marked as a known fact by the speaker, although it is not necessarily the case that the hearer was aware of this fact. Crucially, it thus marks forthcoming old information, a property that also holds of the various «anticipatory» uses of expletive it (cf. Bolinger 1977 for detailed discussion).

Similarly, Hoffmann (2007) shows that tag questions, which arose during the EModE period, only became established in their PDE form towards the end of the EModE period. As Guéron (1980) observes, these are compatible with both old (i.e. specific, presupposed, generic) subjects (cf. *A man is coming with us, isn't one? vs That man is coming with us, isn't he? and Giraffes have long necks, don't they?/A giraffe has a long neck, doesn't it?) and new subjects introduced in 
presentational/existential structures (e.g. There's a lodger living here, isn't there?). Strikingly, the nature of the pronominal element in the tag mirrors the IS status of the associated clause's subject. The fact that fronted non-specific/non-generic indefinites like a man in A man is coming with us cannot give rise to a well-formed tag (cf. again *A man is coming with us, isn't one/there?), however, suggests that tag-formation is sensitive to the IS-status of subjects. More specifically, we would like to suggest that tag-formation systematically involves the pronominal component in question tags duplicating a bundle of $\phi$-features in the target clause which is formally independent of a substantive nominal. In particular, we propose that the salient new-information data highlighted above signalled to late ME/EModE acquirers the need to postulate an IS-«shell» for new DPs, parallel to that which we proposed for old DPs in section 4.3. ${ }^{34}$ Initially, this $n^{*}$ «shell», which we can think of as a [uPerson]-bearing structure parallel to (27), would have been phonologically null. At the point at which Reanalysis II in (30) (i.e. loss of vP-raising) occurred, acquirers would have had to postulate an analysis for salient unraised IA-containing structures of the type illustrated in (36) and also for expletiveless structures like (35) and (37). DP-raising would not have been an option as this would not have delivered the kind of presentational/existential structure present in the input. We therefore propose that they postulated raising of the $n^{*}-\ll$ shell», stranding the new DP in its base position. ${ }^{35}$ This proposal thus facilitates an understanding of the «low» IA-structures discussed in this and the preceding sections that is not available on the B\&R account: for B\&R, loss of vP-raising should lead to the postulation of grammars in which subject raising and expletive insertion become categorical, counter fact; the present proposal allows us see that these structures may have been analysed differently by different speakers during the ME period already, with «conservative» acquirers postulating vP-raising analyses of these structures and «innovative» acquirers postulating $\mathrm{n} *$-raising. In other words, the proposal is that $\mathrm{vP}-$ raising may in fact have been lost at different times by more and less innovative speakers, who were both initially able to produce the same surface structures.

At this point, the role of there-expletives in the grammar of later ME speakers becomes relevant. Biberauer (in prep.a) argues for a grammaticalisation pathway that can be roughly summarised as in (42):

34. We do not rule out the possibility that this new-information «shell» was already part of the OE and earlier ME grammars, i.e. that these grammars formally marked both old- and new-information DPs (and possibly other XPs), just as systems featuring both Topic and Focus markers seem to. It seems plausible that there may be systems marking just old or just new information alongside such double-marking systems, though potentially none not marking either. We leave these important questions for future research.

35. Note that this proposal entails that acquirers postulated movement of a phonologically null element to satisfy T's EPP-requirement, whereas we indicated in connection with parallel old informationrelated $\mathrm{n} *$ in section 4.3 that they would not assume $\mathrm{n} *$-raising independent of an old DP to be possible. There is, however, a crucial difference between the two contexts: in the former, the parent generation's output would not have given acquirers any evidence to postulate independent $n *$ movement - there is no overtly evident reason to assume that old DPs are ever separated from the $\mathrm{n}^{*}$-shells that allow them to be probed twice; in the latter, by contrast, it is clear that new IA-DPs do not undergo movement to Spec-TP, while T's EPP-requirements are nevertheless met. 
(42) a. Grammaticalisation Step $\mathbf{I}:$ deictic $^{36}$ there is reanalysed as discourserelated adjunct specifically signalling the absence of topical material, thus creating a new lexical item alongside deictic there. This element does not bear any formal features and remains a strictly optional element, merged suitably high in the clausal structure, quite plausibly the CP-domain ${ }^{37}$.

b. Grammaticalisation Step II: reanalysis of discourse-related there as a functional discourse head signalling the presence of new information. This element bears [uPerson], making there's valued $\phi$-features ([Person:3; Number:SG $]^{38}$ ) visible to probing heads. Being specifically employed in structures featuring only non-topical (i.e. new) arguments, it is plausible to postulate that this reanalysis also entails there being reanalyzed as a $v P$ peripheral element. ${ }^{39}$ As such, it can be probed by T, triggering agreement of the sort found in there-less PFM structures (cf. (40c)). For some speakers, this step of the grammaticalisation process may also have involved loss of [Number:SG], i.e. introduction of the activating formal feature [uPerson] took place in tandem with the loss of a substantive feature.

c. Grammaticalisation Step III: for some speakers, increasing use of the output(s) of II led to a further reanalysis, in terms of which new-subjectoriented there was analysed as «extra» structure specifically associated with new IAs, i.e. as $\mathrm{n}^{*} .^{40}$ As new IAs already bore phonologically unrealized «extra»structure at this point, this development led to a system with two types of IS-related «extra» structure, realized as zero and there respectively. In respect of there, which in its Stage II form lexicalizes [uPerson; Person:3; Number:SG], the consideration that «extra» structure simply needs to serve an «activating» role, so that the associated nominal can be probed twice, meant that its featural content could become more impoverished: II's [Number:SG] feature could therefore also have been lost at this stage, leaving [uPerson; Person:3] ${ }^{41}$ As pragmatically oriented doubling, unlike subject doubling, may involve either an agreeing or nonagreeing doubling element (cf. D’Alessandro, van Craenenbroeck \& van

36. Note that deictic there should not be confused with locative there; cf. Kayne (2008) for discussion.

37. Williams (2000) shows that the forerunner of PDE expletive there initially became established as a clause-initial element in structures that would otherwise have exhibited V1 ordering. It therefore seems plausible that it may initially have become established as a CP-related discourse-marker (cf. Biberauer 2010 on CP-expletives).

38. That there should inherently be $3^{\text {rd }}$ person singular follows readily if one adopts Kayne's (2008) analysis of deictic there as a complex lexical item which is underlyingly there PLACE. Place is clearly $3^{\text {rd }}$ person singular - cf. This place, it really takes your breath away!

39. Reanalysis of CP-associated there as a vP-related element would at first sight appear to instantiate a case of downwards reanalysis. More accurately, however, this case could be viewed as an instance of parallel grammaticalisation as there «transfers» the discourse-related function it plays at the CP-edge to the edge of the lower phase (cf. Biberauer in prep. b for more detailed discussion).

40. For Biberauer (in prep. b), this instantiates another instance of cross-domain grammaticalisation, this time involving a clause-related element being analysed as a nominal-related one.

41. Strikingly, Zulu may involve a formally very similar system to what is being proposed for ME here - cf. the new subject-containing structure in (26b), which features «expletive» agreement, i.e. non-agreement of the type triggered in existential and presentational structures. 
Koppen $2010^{42}$ ), this Step may in fact entail 2 sub-stages, which may partially have overlapped:

a) there $_{\text {II }}$ is reanalyzed as «extra» structure associated with New IAs (cf. (43ci))

b) there ${ }_{\text {II }}$ loses its Number feature, becoming «more grammaticalised» and thus encoding only minimum of featural content (cf. (43cii)).

(43) a. $\left[_{\mathrm{CP}}\right.$ there ${ }_{[+ \text {deictic, etc ...; Person: 3; Number: } \mathrm{SG} \ldots]} \mathrm{C}\left[_{\mathrm{TP}} \ldots .\left[_{\mathrm{vP}} \ldots\left[_{\mathrm{VP}} \mathrm{V}\left[_{\mathrm{DP}}\right.\right.\right.\right.$ a man $\left.\left.\left.\left.]\right]\right]\right]\right]$

b. $\left[_{\mathrm{CP}} \mathrm{C} \quad\left[_{\mathrm{TP}} \mathrm{T}_{\text {[Case: Nom; uPers; uNumber; } \ldots]}\left[_{\mathrm{vP}}\right.\right.\right.$ there ${ }_{\text {[uPerson; Person: } 3 ; \text { Number: } \mathrm{SG} \ldots . . .} \ldots$ $\left[\mathrm{VP} V{ }_{D P}\right.$ some men $[$ [uCase; Person: $3 ;$ Number: $\left.\left.\left.\left.\mathrm{PL} . .].\right]\right]\right]\right]$

c. (i) $\left[_{\mathrm{n} * \mathrm{P}} \mathrm{n}^{*}=\right.$ there ${ }_{\text {[uPerson; Person: } 3 \text {; Number: } \mathrm{SG} \ldots]}[\mathrm{DP}$ some men $\left.]\right]$

(ii) ${ }_{\mathrm{n} * \mathrm{P}} \mathrm{n}^{*}=$ there $\left.{ }_{[\mathrm{uPerson} ; \text { Person: } 3 ; \ldots]}\right]\left[_{\mathrm{DP}}\right.$ some men]

(i.e. there $=$ the head of $\phi \mathrm{P}$, «extra» IS-related structure associated with IA DP)

Importantly, the outputs of the grammars featuring the theres specified in the above grammaticalisation process would have been very similar since none of them absolutely required the realisation of there in new IA-containing structures, and it is even conceivable that some speakers' lexicons may have included more than one of these theres at a given point. This situation would presumably not have held for a very long time, though, as the function of the various theres is superficially so similar. Once there were speakers who were postulating Stage III-there, however, we have a reached a point where their lexicon features doublets - there and null $\mathrm{n}^{*}$ - serving exactly the same function. Following Kroch (1994), we would not expect this stage to be very long-lasting, with selection in favour of the overtly realised expletive suggesting itself as the most logical outcome, both on account of its phonological recoverability and on account of the existence of a parallel oldinformation expletive, $i$. The fact that numerous non-standard PDE varieties have retained agreement-triggering there (i.e. (43ci)), however, suggests that there was no natural choice to be made between these two options. This follows naturally if we view there not in the first instance as a dummy subject, but, instead, as a pragmatic doubling element which happens to double new-information IA-subjects (cf. again D'Alessandro et al. 2010 on the availability of both agreeing and nonagreeing pragmatic doublers, but the exclusive availability of agreeing subject doublers). Both (43ci)- and (43cii)-type expletives would therefore be expected to survive until an arbitrary decision was made to standardize the latter (cf. i.a. Sobin 1997, Schütze 1999 and Henry 2002 for discussion).

A systematic study of the empirical facts and detailed consideration of the most convincing analysis of these facts, of course, remains to be done. What is

42. Consider the following examples from Wambeek Dutch (D'Alessandro et al. 2010:2):
(i) $\mathrm{Ze}$ komd zaai oek mergen
she- ${ }_{\text {WEAK }}$ comes she- ${ }_{\text {STRONG }}$ also tomorrow
'In spite of what you might think, she's also coming tomorrow.'
(ii) $\mathrm{Ze} \quad$ komd $i j \quad$ oek mergen
she- ${ }_{\text {WEAK }}$ comes he- STRONG $_{\text {also tomorrow }}$
'In spite of what you might think, she's also coming tomorrow.' 
already clear, however, is that recognition of the fact that earlier English featured an IS-sensitive subject system, part of which would have remained accessible to acquirers throughout the ME period and beyond, allows us to view known empirical facts such as variability during the EModE period in the realization of there-and $i t$-expletives and in subject-raising in a more productive light than is possible in the context of a «traditional» Chomsky-style take on the nature of Spec-TP. This perspective also seems likely to shed interesting light on discourse-marked PDE structures like Locative Inversion (On the table stands a lamp), which alternates with a non-discourse-marked there-containing form (On the stable there stands a lamp) and serves a presentational function, introducing one or more new referents. As discourse-marked structures are very frequently relics (consider, for example, Narrative Inversion in Germanic generally), it would not be implausible to propose that Locative Inversion represents a relic of the more conservative, null $\mathrm{n}^{*}$ grammar discussed above. Taking into account earlier English's IS-sensitivity may also facilitate new insight into PDE's poorly understood «impersonal passive» constructions (cf. i.a. Chomsky 2001, Julien 2002b, Rezac 2006 and Bruening 2011 for recent discussion):

(44) a. There were arrested three men

b. There were three men arrested

Contrary to what Chomsky (2001) proposes in his discussion of TH/EX, the IA-subject-placement differences do appear to correlate with interpretive differences (cf. Julien 2002b for discussion). The details would take us too far afield here, but the kind of IS-sensitive diachronic scenario considered in this paper would seem to render at least some of the properties of these passive constructions less mysterious. Similarly, the proposal that the loss of the earlier English IS-sensitive subject system did not in fact give rise to the single canonical subject position of Chomskyan orthodoxy, but, instead, to a new system distinguishing between particular new- and old-information elements allows us to understand the subject-related skewing discussed in Kiss (1996). On the basis of these skewings, Kiss proposes two subject positions for PDE, a lower one (Spec-TP) reserved for non-specific subjects whose existence is asserted, and a higher one (her Spec-RefP) for presupposed (i.e. specific and generic) subjects whose existence is presupposed. Significantly, then, systematic work on OE and PDE subject positions therefore points to continued IS-sensitivity in the subject domain throughout the history of English.

\section{Conclusions and further questions}

Our focus in this paper has been on the following previously un(der)discussed synchronic and diachronic issues:

a) the relation between the early English subject system and English's OV origins; Pivotal here are two key ingredients of the analysis: 1) there was a position higher than Spec, TP which could host discourse-old subjects and pronominal 
objects in Old English; 2) the nature of Spec,TP variously triggered licensing of the subject in Spec,TP, or of little vP which could also include objects (the piedpiping option).

b) the process via which the early English subject system was lost and how this was affected by lexical and word-order considerations. As objects ceased to be scrambled to little $\mathrm{vP}$ over the Middle English period and were thus no longer part of of the vP material that could be piedpiped to Spec,TP, Spec,TP in fact came to host only subjects. Over the late Middle English period, the IS-driven distinction between the higher subject position for discourse-old subjects, and Spec,TP for discourse-new subjects was fading, which rendered the configuration with two subject positions prone to reanalysis into one single subject position. At the same time, there was, however, still robust evidence for a low, VP-internal, subject position in a wide range of unaccusative contexts, which in effect made it impossible for learners to converge on one single analysis for Spec,TP as the single canonical subject position. This led to a new division of labour between particular discourse-old and discourse-new subjects.

c) the nature of the PDE system that ultimately arose from this process: our hypothesis here is that the ambiguity with respect to the evidence for the nature of Spec,TP persists to the present day, and we follow up Kiss (1996), and claim that present-day English continues to show evidence for two subject positions, diversified according to their IS-properties.

Our argument has been that the properties of the IS-sensitive early English system and its subsequent loss can be understood within Biberauer \& Roberts's (2005 et seq.) approach to $\mathrm{OE}$ and ME word-order variation and change once this is informed by van Kemenade and colleagues' work on OE's IS-sensitive subject system and also by recent advances in the understanding of the formal representation of IS properties. This approach leads to the novel and empirically substantiated insight that the «cascade» of word-order changes discussed in Biberauer \& Roberts (2008) cannot in fact have led to the rise of a single, canonical EPP-governed subject position such as that most commonly assumed by generativists; instead, it would seem that the nature of Spec-TP was necessarily unclear to acquirers of late ME and EModE, with surviving remnants of the earlier IS-sensitive system ultimately playing a crucial role in establishing a new IS-sensitive subject system, namely one that exhibits the properties which Kiss (1996) highlights. Many aspects of these proposals require in-depth investigation and refinement that has not been possible to date. Nevertheless, we hope to have given an indication in this paper of how productive serious consideration of Information Structure may well be in developing a fine-grained generatively oriented understanding of diachronic phenomena. 


\section{References}

Aboh, Enoch (2010). «Information structuring begins with the Numeration». Iberia 2-1: 12-42 .

Allen, Cynthia (1995). Case-Marking and Reanalysis: Grammatical Relations from Old to Early Modern English. Oxford: Clarendon Press.

Alexiadou, Artemis; Anagnostopoulou, Elena (1998). «Parametrizing AGR: word order, V-movement, and EPP-checking». Natural Language and Linguistic Theory 16: 491-539.

Ariel, Mira (1988). «Referring and accessibility». Journal of Linguistics 24: 67-87.

Ball, Catherine (1991). The Historical Development of the 'it'-cleft. University of Pennsylvania, doctoral dissertation.

Bech, Kristin (2001). Word Order Patterns in Old and Middle English: A Syntactic and Pragmatic Study. University of Bergen, doctoral dissertation.

Van Bergen, Linda (2002). Pronouns and Word Order in Old English, with Particular Reference to the Indefinite Pronoun Man. London: Routledge.

Biberauer, Theresa (2010). «Semi pro-drop languages, expletives and expletive pro reconsidered». In: Biberauer, Theresa; Holmberg, Anders; Roberts, Ian; Sheehan, Michelle (eds.). Parametric Variation: Null Subjects in Minimalist Theory. Cambridge: CUP, pp. 153-199.

Biberauer, Theresa (2011). A formal approach to information-structure sensitivity in Old English and beyond. University of Cambridge/Stellenbosch, unpublished ms.

Biberauer, Theresa (in prep. a). Grammaticalising an expletive: the case of English there. University of Cambridge/Stellenbosch, unpublished ms.

Biberauer, Theresa (in prep. b). Cross-domain grammaticalisation: an investigation of three 'light' elements. University of Cambridge/Stellenbosch, unpublished ms.

Biberauer, Theresa; Holmberg, Anders; Roberts, Ian (2009). «Linearization and the Architecture of Grammar: a view from the Final-over-Final Constraint». In: Moscati, Vicenzo; Servidio, Emilio (eds.). StiL - Studies in Linguistics (Proceedings of XXXV Incontro di Grammatica Generativa), pp. 78-91.

Biberauer, Theresa; Holmberg, Anders; Roberts, Ian (2010). «A hierarchical universal and its consequences». To appear in Linguistic Inquiry.

Biberauer, Theresa; van Kemenade, Ans (2011). «Predictable and unpredictable changes: the development of the English subject domain». Paper presented at the International Conference on Historical Linguistics (ICHL) 20 (Osaka).

Biberauer, Theresa; Richards, Marc (2006). «True Optionality: when the grammar doesn't mind». In: Boeckx, Cedric (ed.). Minimalist Essays. Amsterdam: Benjamins, pp. 35-67.

Biberauer, Theresa; Roberts, Ian (2005). «Changing EPP-parameters in the history of English: accounting for variation and change». English Language and Linguistics 9-1: 5-46.

Biberauer, Theresa; Roberts, Ian (2006). «The loss of 'head-final' orders and remnant fronting in Late Middle English: causes and consequences». In: Hartmann, Jutta; Molnárfi, Laszlo (eds.). Comparative Studies in Germanic Syntax: From A(frikaans) to Z(ürich German). Amsterdam: Benjamins, pp. 263-297.

Biberauer, Theresa; Roberts, Ian (2008). «Cascading parameter changes: internally driven change in Middle and Early Modern English». In: Eythórsson, Thórhallur (ed.). 
Grammatical Change and Linguistic Theory: the Rosendal Papers. Amsterdam: Benjamins, pp. 79-113.

Biberauer, Theresa; Roberts, Ian (2009). «The Return of the Subset Principle». In: Crisma, Paola; Longobardi, Giuseppe (eds.). Historical Syntax and Linguistic Theory. Oxford: OUP, pp. 58-74.

Biberauer, Theresa; Roberts Ian (2010). «Subjects, Tense and Verb-movement». In: Biberauer, Theresa; Holmberg, Anders; Roberts, Ian; Sheehan, Michelle (eds.). Parametric Variation: Null Subjects in Minimalist Theory. Cambridge: CUP, pp. 263-303.

Biberauer, Theresa; Roberts, Ian (2011). «Negative words and related expressions: a new perspective on some familiar puzzles». In: Ingham, Richard; L'Arrivée, Pierre (eds.). The Evolution of Negation: Beyond the Jespersen Cycle. Berlin: Mouton de Gruyter, pp. 23-60.

Boeckx, Cedric (2003). Islands and Chains. Amsterdam: Benjamins.

Bolinger, Dwight (1977). Meaning and Form. London: Longman.

Breivik, Leif (1983). Existential THERE. Bergen: University of Bergen.

Broekhuis, Hans (2005). «Extraction from subjects: Some remarks on Chomsky's 'On phases'. In: Broekhuis, Hans; Corver, Norbert; Huybrechts, Riny; Kleinhenz, Ursula; Koster, Jan (eds.). Organizing Grammar. Linguistic Studies in Honor of Henk van Riemsdijk. Berlin: Mouton de Gruyter, pp. 59-68.

Bruening, Benjamin (2011). Pseudopassives, Expletive Passives, and Locative Inversion. University of Delaware, unpublished ms.

Buell, L. (2006). «The Zulu Conjoint/Disjoint Verb Alternation: Focus or Constituency?». In: Downing, Laura; Marten, Lutz; Zerbian, Sabine (eds.). ZAS Papers in Linguistics (Papers in Bantu Grammar and Description) 43: 9-30.

Büring, Daniel (1999). «Topic». In: Bosch, Peter; van der Sand, Rob (eds.). Focus Linguistic Cognitive and Computational Perspectives. Cambridge: CUP, pp. 142-165.

Cardinaletti, Anna (1997). «Subjects and clause structure». In: Haegeman, Liliane (ed.). The New Comparative Syntax. London: Longman, pp. 33-63.

Cardinaletti, Anna (2004). «Toward a cartography of subject positions». In: Rizzi, Luigi (ed.). The Structure of CP and IP: The Cartography of Syntactic Structures (volume 2). Oxford: OUP, pp. 115-165.

Cardinaletti, Anna; Starke, Michal (1999). «The typology of structural deficiency: A case study of the three classes of pronouns». In: van Riemsdijk, Henk (ed.). Clitics in the Languages of Europe. Berlin: Mouton de Gruyter, pp. 145-233.

Carstens, Vicki (2010). «Grammatical gender and the theory of uninterpretable features». In: Putnam, Michael (ed.). Exploring Crash Proof Grammars. Amsterdam: Benjamins, pp. 31-57.

Carstens, Vicki (2011). «Hyperactivity and Hyperagreement in Bantu». Lingua 121-5: 721-741.

Cecchetto, Carlo (1999). «A Comparative Analysis of Left and Right Dislocation in Romance». Studia Linguistica 53: 40-67.

Chafe, Wallace (1976). «Givenness, contrastiveness, definiteness, subjects, topics, and point of view». In: Li, Charles (ed.). Subject and Topic. New York: Academic Press, pp. 22-55.

Chafe, Wallace (1987). «Cognitive constraints and information flow». In: Tomlin, Russel (ed.). Coherence and Grounding in Discourse. Amsterdam: Benjamins, pp. 21-51. 
Chomsky, Noam (1981). Lectures on Government and Binding: The Pisa Lectures. Dordrecht: Foris.

Chomsky, Noam (1995). The Minimalist Program. Cambridge, Mass: MIT Press.

Chomsky, Noam (2000). «Minimalist Inquiries: The Framework». In: Martin, Roger; Michaels, David; Uriagereka, Juan (eds.). Step by Step: Essays on Minimalist Syntax in honor of Howard Lasnik. Cambridge, Mass: MIT Press, pp. 89-157.

Chomsky, Noam (2001). «Derivation by phase». In: Kenstowicz, Michael (ed.). Ken Hale. A Life in Language. Cambridge, Mass: MIT Press, pp. 1-52.

Chomsky, Noam (2004). «Beyond explanatory adequacy». In: Belletti, Adriana (ed.). The Cartography of Syntactic Structure (volume 3). Oxford: OUP, pp. 104-131.

Chomsky, Noam (2007). «Approaching UG from below». In: Sauerland, Uli; Gärtner, Hans-Martin (eds.). Interfaces + Recursion = Language? Berlin: Mouton de Gruyter, pp. 1-29.

Chomsky, Noam (2008). «On Phases». In: Freidin, Robert; Oteros, Carlos P.; Zubizarreta, Maria Luisa (eds.). Foundational Issues in Linguistic Theory. Cambridge, MA: MIT Press, pp. 133-166.

Cinque, Guglielmo (1999). Adverbs and Functional Heads. A Crosslinguistic Perspective. Oxford: OUP.

Corver, Norbert (2006). «Freezing effects». In: Everaert, Martin; van Riemsdijk, Henk (eds.). The Blackwell Companion to Syntax (Volume II) Malden, Mass: Backwell, pp. 383-406.

D’Alessandro, Roberta; van Craenenbroeck, Jeroen; van Koppen, Marjo (2010). «Pronominal doubling in Germanic and Romance». Paper presented at the $4^{\text {th }}$ European Dialect Syntax Workshop (San Sebastian) [Available on-line at: http://www.hum.uu.nl/ medewerkers/j.m.vankoppen/handouts/handout\%20basdiasyn\%20workshop.pdf]

Deal, Amy Rose (2009). «The origin and content of expletives: evidence from 'selection'». Syntax 12-4: 285-323.

Diesing, Molly (1992). Indefinites. Cambridge, Mass: MIT Press.

Dryer, Matthew (1996). «Focus, pragmatic presupposition and activated propositions». Journal of Pragmatics 26: 475-523.

Elenbaas, Marion (2007). The Synchronic and Diachronic Syntax of the English VerbParticle Combination. Leiden University, doctoral dissertation.

Fischer, Olga; van Kemenade, Ans; Koopman, Willem; van der Wurff, Willem (eds.) (2000). The Syntax of Early English. Cambridge: CUP.

Frascarelli, Mara; Hinterhölzl, Roland (2007). «Types of Topics in German and Italian». In: Winkler, Susanne; Schwabe, Kerstin (eds.). On Information Structure, Meaning and Form. Amsterdam: Benjamins, pp. 87-116.

Guéron, Jacqueline (1980). «On the syntax and semantics of PP extraposition». Linguistic Inquiry 11: 637-678.

Givón, Talmy (1983). «Topic Continuity in Discourse: An Introductionw. In: Givón, Talmy (ed.). Topic Continuity in Discourse: A Quantitative Crosslanguage Study. Amsterdam: Benjamins, pp. 5-41.

Grohmann, Kleanthes; Ingham, Richard (2009). «Expletive pro and Misagreement in Late Middle English». In: Crisma, Paola; Longobardi, Giuseppe (eds.). Historical Syntax and Linguistic Theory. Oxford: OUP, pp.311-328.

Gundel, Jeanette; Hedberg, Nancy; Zacharski, Ron (1993). «Cognitive status and the form of referring expressions in discourse». Language 69: 274-308. 
Haeberli, Eric (1999). Features, Categories and the Syntax of A-positions. Synchronic and Diachronic Variation in the Germanic languages. University of Geneva, doctoral dissertation.

Haeberli, Eric (2002). Features, Categories and the Syntax of A-Positions. CrossLinguistic Variation in the Germanic Languages. Dordrecht: Kluwer.

Haegeman, Liliane; van Riemsdijk, Henk (1986). «Verb Projection Raising, scope and the typology of rules affecting verbs». Linguistic Inquiry 7: 417-466.

Heim, Irene (1982). The Semantics of Definite and Indefinite Noun Phrases. UMass Amherst, doctoral dissertation.

Henry, Alison (2002). «Variation and Syntactic Theory». In: Chambers, Janet; Trudgill, Peter; Schilling-Estes, Natalie (eds). The Handbook of Language Variation and Change. Oxford: Blackwell, pp. 267-282.

Hinterhölzl, Roland; Petrova, Svetlana (2009). «From V1 to V2 in West Germanic». Lingua 120: 315-328.

Hoffmann, Stefan (2007). «Tag questions in Early and Late Modern English». Anglistik 17(2): $35-55$.

Huang, C.T. James (1982). Logical relations in Chinese and the theory of grammar. MIT, doctoral dissertation.

Ingham, Richard (2001). «The structure and function of expletive there in premodern English». Reading Working Papers in Linguistics 5: 231-249.

Ingham, Richard (2003). «The development of the expletive negative construction in Middle English». Transactions of the Philological Society 101(3): 411-452.

Jonas, Dianne (1996). Clausal Structure and Verbal Syntax of Scandinavian and English. Harvard University, doctoral dissertation.

Julien, Marit (2002a). Syntactic Heads and Word Formation: A Study of Verbal Inflection. New York: OUP.

Julien, Marit (2002b). On the syntax of TH/EX. University of Troms $\varnothing$, unpublished ms. [Available at: http://www.punksinscience.org/kleanthes/courses/UK03S/OSPS/ Julien.pdf]

Kahnemuyipour, Arsalan (2009). The Syntax of Sentential Stress. Oxford: OUP.

Kallulli, Dalina (2000). «Direct Object Clitic Doubling in Albanian and Greek». In: Beukema, Frits; den Dikken, Marcel (eds.). Clitic Phenomena in European Languages. Amsterdam: Benjamins, pp. 209-248.

Kayne, Richard (1991). «Romance Clitics, Verb Movement and PRO». Linguistic Inquiry 22: 647-686.

Kayne, Richard (1994). Antisymmetry in Syntax. Cambridge, Mass: MIT Press.

Kayne, Richard (2008). «Expletives, datives, and the tension between morphology and syntax». In: Biberauer, Theresa (ed.). The Limits of Syntactic Variation. Amsterdam: Benjamins, pp. 175-218.

Kemenade, Ans van (1987). Syntactic Case and Morphological Case in the History of English. Dordrecht: Foris.

Kemenade, Ans van (1997). «V2 and embedded topicalisation in Old and Middle English». In: van Kemenade, Ans; Vincent, Nigel (eds.). Parameters of Morphosyntactic Change. Cambridge: CUP, pp. 326-352.

Kemenade, Ans van (1999). «Sentential negation and word order in Old English». In: Tieken-Boon van Ostade, Ingrid, Tottie, Gunnel; van der Wurff, Wim (eds.). Negation in the History of English. Berlin: Mouton de Gruyter, pp. 147-166. 
Kemenade, Ans van (2000). «Jespersen's Cycle revisited: formal properties of grammaticalization». In: Pintzuk, Susan; Tsoulas, George; Warner, Anthony (eds.). Diachronic Syntax: Models and Mechanisms. Oxford: OUP, pp. 51-75.

Kemenade, Ans van; Los, Bettelou (2006). «Discourse Adverbs and Clausal Syntax in Old and Middle English». In: van Kemenade, Ans van; Los, Bettelou (eds.). The Handbook of the History of English. Oxford: Blackwell, pp. 224-248.

Kemenade, Ans van; Milicev, Tanja (2005/2012). «Syntax and discourse in Old English word order». In: Jonas, Dianne; Garrett, Andrew; Whitman, John (eds.). Syntactic Change: Origins, Development, Outcomes. Oxford: OUP, pp. 239-154.

Kemenade, Ans van; Milicev, Tanja; Baayen, Harald (2008). «The balance between discourse and syntax in Old English». In: Dossena, Marina; Gotti, Maurizio (eds.). English Historical Linguistics 2006, Volume I: Syntax and Morphology. Amsterdam: Benjamins, pp. 3-22.

Kemenade, Ans van; Westergaard, Marit (in press). «Syntax and Information Structure: V2 variation in Middle English». In: López-Couso, María José; Los, Bettelou; MeurmannSolin, Anneli (eds.). Information Structure and Syntactic Change. Oxford: OUP.

Kiss, Katalin (1996). «Two subject positions in English». The Linguistic Review 13(2): 119-142.

Ko, Hee-Jong (2005). Syntactic Edges and Linearization. MIT, doctoral dissertation.

Koopman, Willem (1994). The order of dative and accusative objects in Old English. University of Amsterdam, unpublished ms.

Kramer, Ruth (2010). «The Amharic definite marker and the syntax-morphology interface». Syntax 13: 196-240.

Kroch, Anthony (1989). «Reflexes of grammar in patterns of language change». Language Variation and Change 1: 199-244.

Kroch, Anthony (1994). «Morphosyntactic variation». In: Beals, Karen et. al. (eds.). Papers from the 30th Regional Meeting of the Chicago Linguistics Society: Parasession on Variation and Linguistic Theory, pp. 180-201.

Kroch, Anthony; Taylor, Ann (2000a). The Penn-Helsinki Parsed Corpus of Middle English (PPCME). Philadelphia: University of Pennsylvania.

Kroch, Anthony; Taylor, Ann (2000b). «Verb-object order in Early Middle English». In: Pintzuk, Susan; Tsoulas, George; Warner, Antony (eds.). Diachronic Syntax: Models and Mechanisms. Oxford: OUP, pp.132-163.

Kuno, Susumo (1976). «Subject, theme, and the speaker's empathy - a reexamination of relativization phenomena». In: Li, Charles (ed.). Subject and Topic. New York: Academic Press, pp. 417-444.

Lambrecht, Knud (1994). Information Structure and Sentence Form. Topic, Focus and the Mental Representations of Discourse Referents. Cambridge: CUP.

Lambrecht, Knud (2001). «A framework for the analysis of cleft constructions». Linguistics 39(3): 463-516.

Links, Meta (2010). 'But Ther Could No Man Shew Me Which was Your Ground': Exploring the Transitive Expletive Construction in Earlier English. Paper presented at the Symposium on the History of English Syntax (SHES) 2010.

López, Luis (2009). A Derivational Syntax for Information Structure. New York: OUP.

McNally, Louise (1998). «On the linguistic encoding of information packaging instructions». In: Culicover, Peter; McNally, Louise (eds.). The Limits of Syntax. New York: Academic Press, pp. 161-84. 
Müller, Gereon (2009). «On deriving CED effects from the PIC». Linguistic Inquiry 41(1): 35-82.

Müller, Gereon (2010). Movement from Verb Second Clauses Revisited. University of Leipzig, unpublished ms. [Available on-line at: http://www.uni-leipzig. de/ muellerg/mu239.pdf]

Neeleman, Ad; Titov, Elena; van de Koot, Hans; Vermeulen, Reiko (2010). «A syntactic typology of topic, focus and contrast». In: Craenenbroeck, Jeroen van (ed.). Alternatives to Cartography. Berlin: Mouton de Gruyter, pp. 15-51.

Niyogi, Partha (2006). The Computational Nature of Language Learning and Evolution. Cambridge, Mass: MIT Press.

Nunes, Jairo; Uriagereka, Juan (2000). «Cyclicity and extraction domains». Syntax 3 (1): 20-43.

Pesetsky, David (1987). «Wh-in-situ: Movement and unselective binding». In: Reuland, Eric; Meulen, Alice ter. (eds). The Representation of (In)Definiteness. Cambridge, MA: MIT Press, pp. 98-129.

Pesetsky, David (2000). Phrasal Movement and Its Kin. Cambridge, Mass: MIT Press.

Pintzuk, Susan (1991). Phrase Structure in Competition: Variation and Change in Old English Word Order. University of Pennsylvania, doctoral dissertation.

Pintzuk, Susan (1999). Phrase Structures in Competition. Variation and Change in Old English Word Order. New York: Garland.

Pintzuk, Susan; Haeberli, Eric; van Kemenade, Ans; Koopman, Willem; Beths, Frank (2000). The Brooklyn-Geneva-Amsterdam-Helsinki Parsed Corpus of Old English. York: Department of Language and Linguistic Science.

Prince, Ellen (1978). «A comparison of wh-clefts and it-clefts in discourse». Language 54: 883-906.

Prince, Ellen (1981). «Toward a taxonomy of given/new information». In: Cole, Peter (ed.). Radical Pragmatics. New York: Academic Press, pp. 213-255.

Prince, Ellen (1992). «Subject, definiteness, and information-status. In: Mann, William; Thompson, Sandra (eds.). Discourse Description: Diverse Linguistic Analysis of a Fund-Raising Text. Amsterdam: Benjamins, pp. 295-325.

Reinhart, Tanya (1981). «Pragmatics and Linguistics: An Analysis of Sentence Topics». Philosophica 27: 53-94.

Rezac, Milan (2006). «The Interaction of TH/EX and Locative Inversion». Linguistic Inquiry 37: 685-697.

Richards, Marc (2008). «Defective Agree, Case Alternations, and the Prominence of Person». In: Richards, Marc; Malchukov, Andrej (eds.). Linguistische Arbeitsberichte 86 (Scales): 137-161.

Richards, Marc; Biberauer, Theresa (2005). «Explaining Expl». In: den Dikken, Marcel; Tortora, Christina (eds.). The Function of Function Words and Functional Categories. Amsterdam: Benjamins, pp. 115-154.

Rizzi, Luigi (1997). Parameters and Functional Heads: Essays in Comparative Syntax. Oxford: Oxford University Press.

Van Riemsdijk, Henk (1998). «Categorial Feature Magnetism. The endocentricity and distribution of projections». Journal of Comparative Germanic Linguistics 2: 1-48.

Roberts, Ian (1997). «Restructuring, Head Movement and Locality». Linguistic Inquiry 28: 423-460. 
Roberts, Ian. (2010). Agreement and Head Movement. Clitics, Incorporation, and Defective Goals. Cambridge, MA: MIT Press.

Roberts, Ian; Roussou, Anna. (2003). Syntactic Change. A Minimalist Approach to Grammaticalisation. Cambridge: CUP.

Schütze, Carson (1999). «English expletive constructions are not infected». Linguistic Inquiry 30: 467-484.

Sobin, Daniel (1997). «Agreement, default rules, and grammatical viruses». Linguistic Inquiry 28: 318-343.

Strawson, Peter (1964). «Identifying reference and truth values». Theoria 30: 96-118.

Tanaka, Tomoyuki (2000). «On the development of transitive expletive constructions in the history of English». Lingua 7: 473-495.

Tanaka, Tomoyuki (2002). «Synchronic and Diachronic Aspects of Overt Subject Raising in English». Lingua 112: 619-646.

Taylor, Ann; Warner, Anthony; Pintzuk, Susan; Beths, Frank (2003). The York-TorontoHelsinki Parsed Corpus of Old English Prose (YCOE). York: Department of Language and Linguistic Science.

Taylor, Ann; Pintzuk, Susan (2011). «VO order, clause type and information status in Old English». To appear in: Biberauer, Theresa; Walkden, George (eds.). Peripheries Past and Present: The Interaction of Information Structure, Prosody and Syntax. Oxford: OUP.

Taylor, Ann; Pintzuk, Susan (to appear). «The effect of information structure on object position in the history of English». To appear in: Los, Bettelou; López-Couso, María José; Meurman-Solin, Anneli (eds.). Information Structure and Syntactic Change. Oxford: OUP.

Tenny, Carol (2000). «Core Events and Adverbial Modification». In: Tenny, Carol; Pustejovsky, James (eds.). Events as Grammatical Objects. Stanford: CSLI Publications, pp. 285-334.

Travis, Lisa (2006). «VP, $\mathrm{D}^{0}$ movement languages». In: Zanuttini, Raffaella; Campos, Hector; Herburger, Elena; Portner, Paul (eds.). Negation, Tense and Clausal Architecture: Cross-linguistic Investigations. Washington, D.C.: Georgetown University Press, pp. 127-147.

Trips, Carola (2002). From OV to VO in Early Middle English. Amsterdam: Benjamins.

Uriagereka, J. (1995). «Aspects of the Syntax of Clitic Placement in Western Romance». Linguistic Inquiry 26: 79-123.

Vallduví, Enric (1992). The Informational Component. New York: Garland.

Van der Wal, Jenneke (2009). Word Order and Information Structure in MakhuwaEnahara. Leiden, doctoral dissertation.

Vikner, Sten (2005). «Immobile Complex Verbs in Germanic». Journal of Comparative Germanic Linguistics 8-1/2: 83-115.

Wallenberg, Joel. (2009). Antisymmetry and the Conservation of C-Command: Scrambling and Phrase Structure in Synchronic and Diachronic Perspective. UPenn, doctoral dissertation.

Walkden, George (2011). «Verb-third in early West Germanic: a comparative perspective». To appear in: Biberauer, Theresa; Walkden, George (eds.). Peripheries Past and Present: The Interaction of Information Structure, Prosody and Syntax. Oxford: OUP.

Warner, Anthony (1993). English Auxiliaries: Structure and History. Cambridge: CUP. 
Warner, Anthony (2007). «Parameters of variation between verb-subject and subjectverb order in late Middle English». English Language and Linguistics 11: 81-111.

Westergaard, Marit (2005). «Norwegian child language and the history of English: The interaction of syntax and information structure in the development of word order». In: McCafferty, Kevin; Bull, Tove; Killie, Kristin (eds.). Contexts - Historical, Social, Linguistic. Studies in Celebration of Toril Swan. Bern: Peter Lang, pp. 293-310.

Williams, A. (2000). «Null subjects in Middle English existentials». In: Pintzuk, Susan; Tsoulas, George; Warner, Anthony (eds.). Diachronic Syntax: Models and Mechanisms. Oxford: OUP, pp. 164-190.

Wurmbrand, Susanne (2001). Infinitives: Restructuring and Clause Structure. Berlin: Mouton de Gruyter.

Yang, Charles (2002). Knowledge and Learning in Natural Language. Oxford: OUP.

Zeller, Jochen (2008). «The Subject Marker in Bantu as an Antifocus Marker». Stellenbosch Papers in Linguistics 38: 221-254.

Zwicky, Arnold; Pullum, Geoffrey (1983). «Cliticization versus inflection: English $n ’ t$. Language 59: 502-513. 